ANSP-M-7

JANUARY 1974

Copy No. 28

Aerospace Nuclear Safety Program

\title{
EVALUATION OF METHODS USED TO DETERMINE TEMPERATURES \\ OF CONVECTIVELY HEATED SOLID SURFACES
}

by J. D. RANDALL

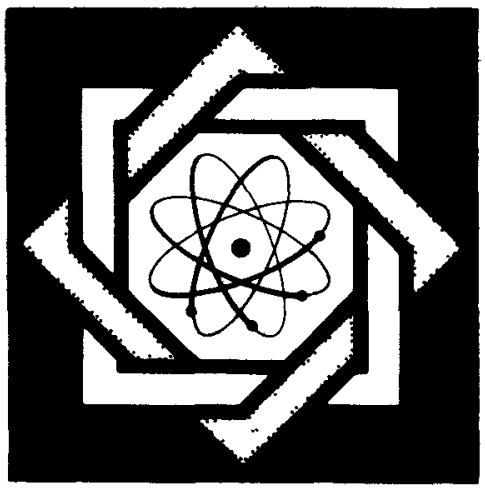

THE JOHNS HOPKINS UNIVERSITY - APPLIED PHYSICS LABORATORY 


\section{DISCLAIMER}

This report was prepared as an account of work sponsored by an agency of the United States Government. Neither the United States Government nor any agency Thereof, nor any of their employees, makes any warranty, express or implied, or assumes any legal liability or responsibility for the accuracy, completeness, or usefulness of any information, apparatus, product, or process disclosed, or represents that its use would not infringe privately owned rights. Reference herein to any specific commercial product, process, or service by trade name, trademark, manufacturer, or otherwise does not necessarily constitute or imply its endorsement, recommendation, or favoring by the United States Government or any agency thereof. The views and opinions of authors expressed herein do not necessarily state or reflect those of the United States Government or any agency thereof. 


\section{DISCLAIMER}

Portions of this document may be illegible in electronic image products. Images are produced from the best available original document. 
ANSP-M-7

JANUARY 1974

Aerospace Nuclear Safety Program

EVALUATION OF METHODS USED TO DETERMINE TEMPERATURES OF CONVECTIVELY HEATED SOLID SURFACES

by J. D. RANDALL

This repurt was prepared ds an account of work
sponsored by the United States Government. Neither
the United States nor the United States Atomic Energy
Commission, nor any of their employees, nor any of
their contractors, subcontractors, or theu employees,
makes any warranty, express or implied, or assumes any
legal liability or responsibility for the accuracy, com-
pleteness or usefulness of any information, apparatus,
product or process disclosed, or represents that its use
would not infringe privately owned rights.

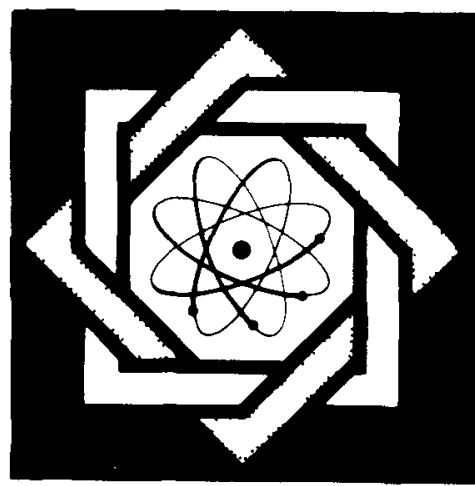

THE JOHNS HOPKINS UNIVERSITY • APPLIED PHYSICS LABORATORYY

8621 Georgia Avenue 。 Silver Spring, Maryland 。 20910 
The work reported herein was conducted by the Aeronautics Division of the Applied Physics Laboratory for the Atomic Energy Commission Safety Branch, Space Nuclear Systems Office. Activities of the Aeronautics Division are under the general supervision of $\mathrm{Dr}$. William $\mathrm{H}$. Avery. The Project Engineer for the Aerospace Nuclear Safety Program is James C. Hagan. 
This report is a survey of several explicit numerical methods for calculating the surface temperature of a one dimensional slab subjected to convective heating. The surface conductance and all thermal properties are assumed to be constant. Graphical comparisons of numerical and exact solutions are presented. Some rules of nodal definition based on consistency requirements are established. 


\section{SUMMARY}

A review of various numerical methods used in the BBE Standard Heat Transfer Program (SHTP) has revealed inconsistencies in the evaluation of temperatures of convectively heated solid surfaces and nodes adjacent to those surfaces. On the surfaces the inconsistency is connected with neglected higher order terms in evaluating the solid's thermal conduction at the solidfluid interface. At the first node adjacent to the surface, the rodal heat balance is inconsistent with the node" $s$ differential equation.

In order to evaluate the seriousness of these inconsistences and compare advantages and disadvantages of alternative methods, four numerical methods of evaluating surface temperatures were used and compared to analytical solutions. It is recommended that the SHTP's method of surface temperature evaluation be changed from Method II discussed in this memo to Method III discussed in this memo. 


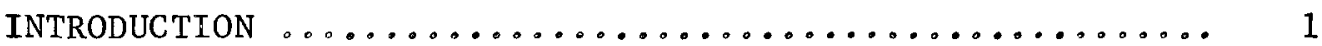

SURFACE TEMPERATURE EVALUATION METHODS............. 2

METHOD I, SURFACE VOLUME ELEMENT METHOD .......... 5

METHOD II, DUSINBERRE LUMPING METHOD............ 5

METHOD III, IMPROVED WALL CONDUCTION ESTIMATION..... 11

METHOD IV, THE ELROD METHOD................. 13

COMPARISONS OF NUMERICAL AND EXACT SOLUTIONS........... 15

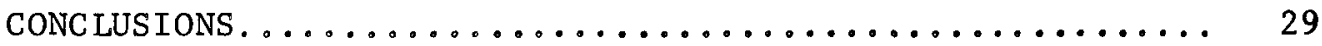

REFERENCES. .................................... 30

APPENDIX A: CONSISTENCY IN ONE-DIMENSIONAL VARIABLE

PROPERTY SYSTEMS.................. 31

AFPENDIX B: GENERALIZED IWC................. 33

AFPENDIX C: EXACT SOLUTIONS OF THE SLAB PROBLEM........ 36

APPENDIX D: SOME FURTHER REMARKS ABOUT IWC AND SVE...... 38 
FIGURE 1: SIAB CONFIGURATION.................. 2

FIGURE 2: UNIFORM GRID SYSTEM................ 4

FIGURE 3: DUSINBERRE GRID SYSTEM. ............... 6

FIGURE 4: NODAL VOLUME ARRANGEMENT.............. 10

FIGURE 5: COMPUTATIONAL ERRORS................. 16

FIGURE $6: \quad$ COMPUTATIONAL ERRORS................ 17

FIGURE 7: COMPUTATIONAL ERRORS................ 18

FIGURE 8: COMPUTATIONAL ERRORS................. 19

FIGURE 9: COMPARISON OF SURFACE TEMPERATURE METHODS..... 23

FIGURE 10: COMPARISON OF SURFACE TEMPERATURE METHODS..... 24

FIGURE 11: EARLY TIME SURFACE TEMPERATURES........... 26

FIGURE $12:$ COMPUTATIONAL ERRORS............... 27

FIGURE 13: COMPUTATIONAL ERRORS............... 28

FIGURE B-1: NON UNIFORM GRID FOR SURFACE

TEMPERATURE ESTIMATION................. 34 
THE JOHNS HOPKINS UNIVERSITY

APPLIED PHYSICS LABORATORY

Silver SPRING Maryland

LIST OF TABLES

Page

TABLE 1: SPATIAL GRID SIZES AND MAXIMUM TIME STEPS...... 21

TABLE 2: ERRORS NOT PLOTTED IN FIGURES 5 THROUGH $8 \ldots \ldots . .22$ 


\section{INTRODUCTION}

The purpose of this memo is to report on various methods of ejaluating solid surface temperatures of materials subjected to convective heating. This study was undertaken because of two inconsistencies discovered in surface temperature evaluation techniques used in $A P L^{p}$ \& Standard Heat Transfer Program (SHTP).

For purposes of the investigation, the following problem, sketcised in Figure 1, was considered. An infinite flat plate with thickness $2 \mathrm{~L}=1^{\prime \prime}$ is immersed in a bath which convectively heats or cools it. The convective heat transfer coefficient, $h$, is assumed to be constant, as are the slab's thermal properties $k$ (thermal conductivity), $p$ (density), c (specific heat), and $\alpha$ (thermal diffusivity). The slab's properties are chosen to be typical of T-50 graphite composite materiali which is being used as a protective material for General Electric's MHW/HSA which is currently being evaluated by API, while the slab thickness, $2 \mathrm{~L}, \mathrm{~h}$, and the bath temperature are chosen to provide typical heating rates occurring when devices protected by $T-50$ reenter the earth ${ }^{8} \mathrm{~s}$ atmosphere.

The slab"s initial temperature, $T_{0}$, is assumed to be uniform. The bath temperature, $T_{\infty}$, is assumed to be:

$$
T_{\infty}=T^{*}+F(t)
$$




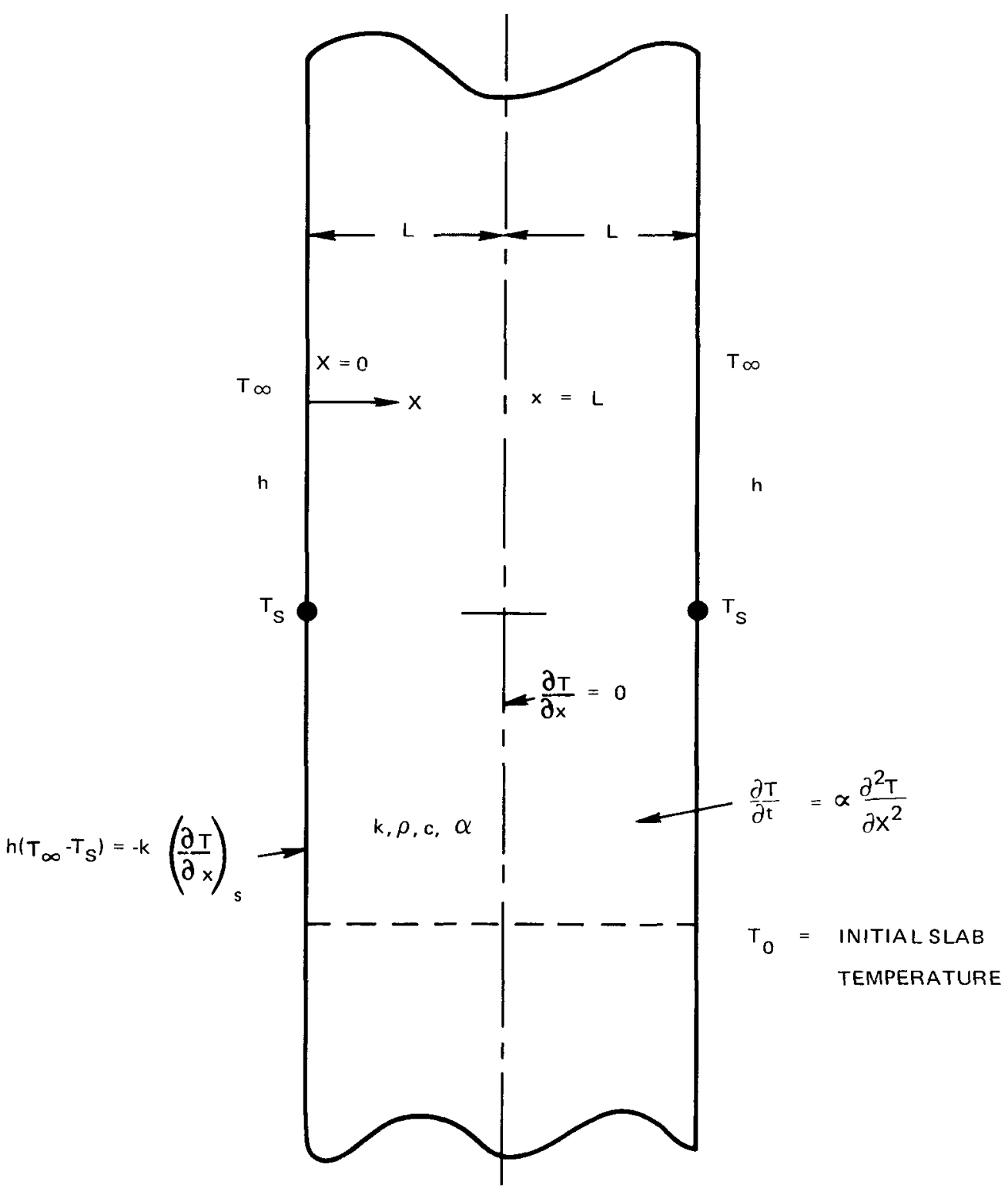

(U) Fig. 1 SLAB CONFIGURATION (U) 
where $T^{*}$ is a constant temperature and $F(t)$ (where $t$ is $t i m e$ ) is an arbitrary function of time.

Due to the symmetry of the problem, the slab centerline is adiabatic and only half of the slab need be considered. The slab's temperature, $T$, as a function of $x$ (defined in Figure 1 ) and $t$ is governed by the onedimensional constant coefficient heat equation ${ }^{2}$ :

$$
\frac{\partial T}{\partial t}=\frac{\alpha \partial^{2} T}{\partial x^{2}}
$$

Temperature histories of the slab were determined analytically and by four different finite difference methods, which differ mainly in the way in which they treat the calculation of surface temperatures.

\section{SURFACE TEMPERATURE EVALUATION METHODS}

The surface boundary condition for the problem being considered is a heat flux boundary condition, i.e.:

$$
h\left(T_{\infty}-T_{s}\right)=-k\left(\frac{\partial T}{\partial x}\right)_{s}
$$

where the subscript $s$ denotes the solid surface $(x=0)$. The other boundary condition is the zero heat flux condition at the slab center $(x=L)$.

Various finite difference techniques are available which make use of equation 3 in some way to determine the surface temperature $T_{S}$. Some of tnese methods can lead to reductions in the maximum permissible time step which can be used in a finite difference calculation ${ }^{3}$. It would be desirable if this time step were determined solely by interior point stability considerations.

If $T_{i-1}, T_{i}$, and $T_{i+1}$ represent temperatures at three successive nodes separated from each other by a distance $\Delta x$ and $T_{i}^{+}$represents $T_{i}$ at a time $\Delta t$ later, it is well known that an explicit finite difference analysis ${ }^{2}$ at the spatial point i leads to:

$$
\mathrm{T}_{i}^{+}=(1-2 \mathrm{r}) \mathrm{T}_{i}+\mathrm{r}\left(\mathrm{T}_{\mathrm{i}+1}+\mathrm{T}_{\mathrm{i}-1}\right)
$$

where:

$$
r=\frac{\alpha \Delta t}{\Delta x^{2}}
$$


THE JOHNS HOPKINS UNIVERSITY

APPLIED PHYSICS LABORATORY

SILVER SPRING MARYLAND

Page 4.

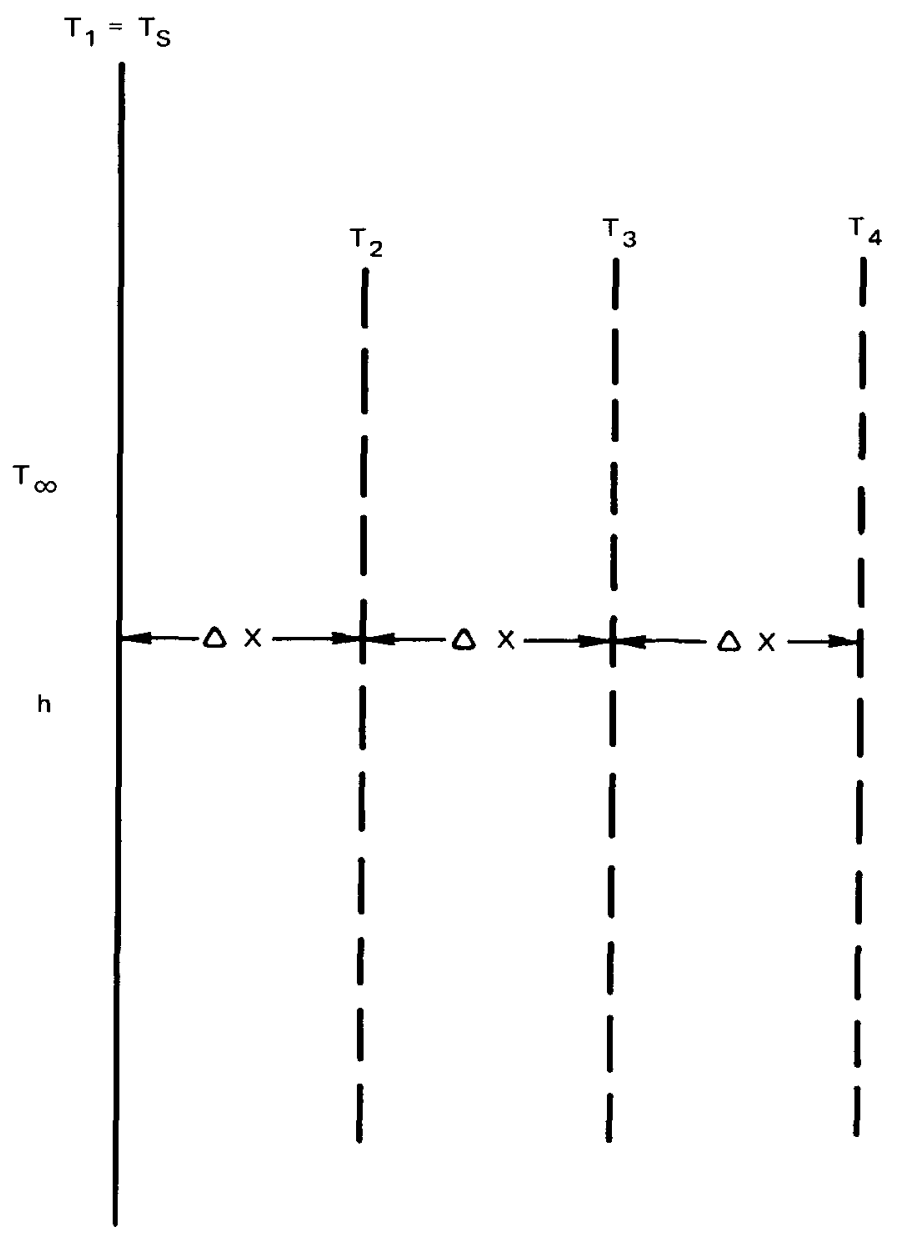

(U) Fig. 2 UNIFORM GRID SYSTEM (U) 
Stable results can be obtained from equation 4 if $^{2}$ :

$$
r \leq \frac{1}{2}
$$

This is the interior point stability criterion.

Four methods of determining surface temperatures will be considered here.

Method I, Surface Volume Element Method (SVE):

This is probably the most widely known method of surface temperature evaluation ${ }^{2}, 4$ and was used for several years in the SHTP ${ }^{5}$. Essentially it derives from an energy balance on a half volume element of $\Delta x / 2$ adjacent to the surface (See Figure 2). The new surface temperature $\mathrm{T}_{1}^{+}$ is :

$$
\mathrm{T}_{1}^{+}=\mathrm{T}_{1}(1-2 \mathrm{r}(1+\mathrm{M}))+2 \mathrm{rT} \mathrm{T}_{2}+2 \mathrm{MrT} \mathrm{T}_{\infty}
$$

where:

$$
M=\frac{n \Delta x}{k}
$$

Stable results can be obtained from equation 7 if:

$$
\mathrm{r} \leq \frac{1}{2(1+\mathrm{M})}
$$

Since $M>0$, this leads to smaller time steps than equation 6 does and thus requires longer computation times to reach a particular time in a temperature history calculation. For high convective heating rates, $M$ becomes very large and computation costs can become prohibitive due to the required smaller time steps. For this reason, Allen ${ }^{3}$ proposed that the SHTP use the following method, due to Dusinberre ${ }^{6}$, in which the time step does not approach zero as $M$ approaches infinity.

Method II, Dusinberre Lumping Method (DLM):

The object of this method is to enhance numerically stable time steps by eliminating the need for a mass in connection with the surface temperature $T_{1}$. Dusinberre ${ }^{6}$ proposed to do this by shifting node 2 in Figure 2 toward node 1 so that node 1 's mass is zero. This results in the grid system shown in Figure 3 . If node 1 has no mass, its heat balance equation is : 


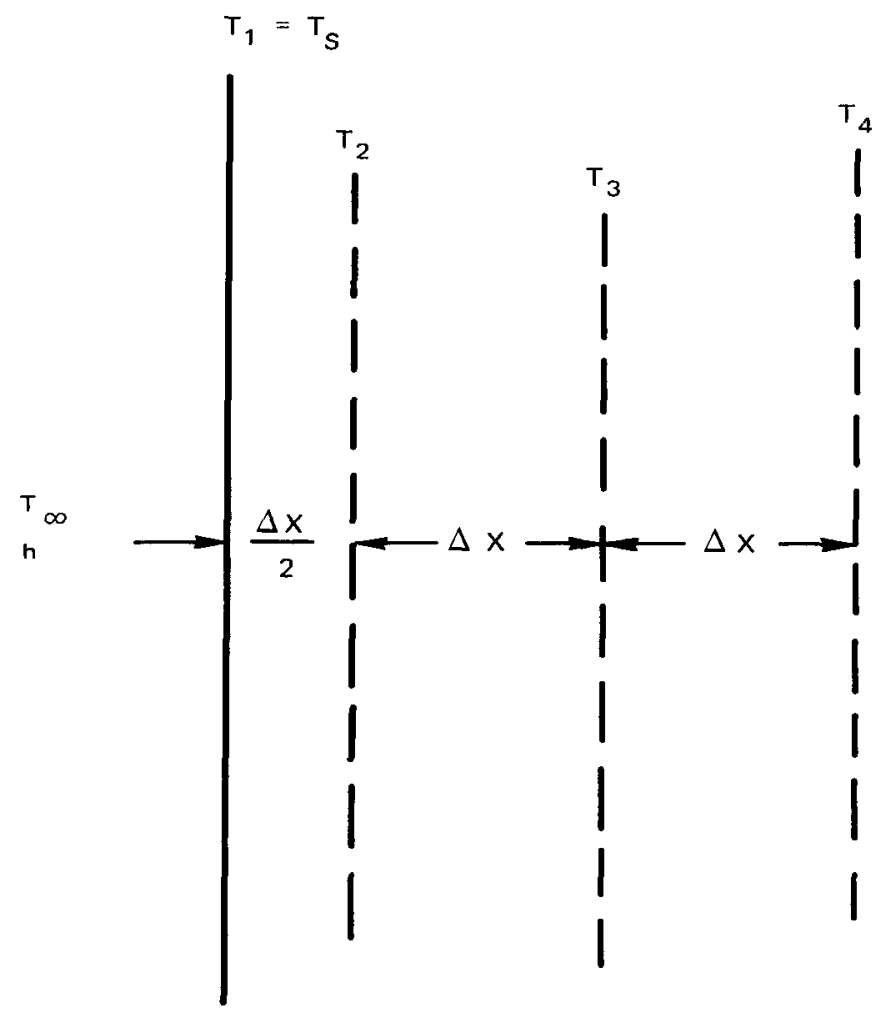

(U) Fig. 3 DUSINBERRE GRID SYSTEM (U) 
and if node $2^{\prime} \mathrm{s}$ mass is $\Delta \Delta x$, then:

$$
\frac{2 k}{\Delta x}\left(T_{1}-T_{2}\right)=\rho c \Delta x \frac{\left(T_{2}^{+}-T_{2}\right)}{\Delta t}+\frac{k}{\Delta x} \quad\left(T_{2}-T_{3}\right)
$$

Solving equation 10 for $\mathrm{T}_{1}$ and equation 11 for $\mathrm{T}_{2}^{+}$gives:

$$
\begin{gathered}
\mathrm{T}_{1}=\frac{\mathrm{T}_{2}+\frac{\mathrm{M}}{2} \mathrm{~T}_{\infty}}{1+\frac{\mathrm{M}}{2}} \\
\mathrm{~T}_{2}^{+}=\mathrm{T}_{2}(1-3 \mathrm{r})+2 r \mathrm{~T}_{1}+\mathrm{rT}_{3}
\end{gathered}
$$

Equation 12 has no stability requirement but equation 13 requires that:

$$
r \leq \frac{1}{3}
$$

which is somewhat more restrictive than the interior point stability requirement but does not lead to shrinking time steps with increasing M. This advantage of DLM has led to its incorporation into the SHTP.

Unfortunately, equations 10 and 11 are incorrect. The reasons for this will be outlined in the following paragraphs.

Any finite difference analysis is undertaken to obtain approximate solutions to differential equations. In thermal analysis, engineers often make "energy balances" on "nodes" which result in finite difference approximations (FDA's) which are used to replace the differential Fourier heat conduction equation. As most heat transfer texts show, the 1 imit of such "nodal" energy balances is the required differential heat equation. To elaborate, as smaller grid spacings are used, the solutions of finite difference equations should approach the solutions of the differential equations which they represent. In order to do this, the finite difference equation should become the differential equation in the limit of zero grid spacing. This requirement is known as consistency. $\operatorname{Smith}^{8}$ has pointed out that numerical 
algorithms which are stable and use consistent FDA's are necessary to obtain solutions which converge to the solution of the differential equation as grid spacings are shrunk. This will not happen with inconsistent FDA's. In other words, convergence to the correct solution requires both stability and consistency.

The major objection to DLM is that its FDA at node 2 is inconsistent, $i . e$. equation 11 will not yield equation 2 as $\Delta x$ and $\Delta t$ approach zero. Slight rearrangement of equation 11 gives

$$
D C \frac{\left(\mathrm{T}_{2}^{+}-\mathrm{T}_{2}\right)}{\Delta \mathrm{t}}=\frac{\mathrm{k}}{\Delta \mathrm{x}^{2}} \quad\left(2 \mathrm{~T}_{1}-3 \mathrm{~T}_{2}+\mathrm{T}_{3}\right)
$$

In order to check for consistency, $\mathrm{T}_{2}^{+}, \mathrm{T}_{1}$, and $\mathrm{T}_{3}$ are expanded about $\mathrm{T}_{2}$ in Taylor series:

$$
\begin{gathered}
\mathrm{T}_{2}^{+}=\mathrm{T}_{2}+\Delta t\left(\frac{\partial \mathrm{T}}{\partial \mathrm{t}}\right)_{2}+\frac{\Delta t^{2}}{2 !}\left(\frac{\partial^{2} \mathrm{~T}}{\partial \mathrm{t}^{2}}\right)_{2}+\cdots \\
\mathrm{T}_{1}=\mathrm{T}_{2}-\frac{\Delta \mathrm{x}}{2}\left(\frac{\partial \mathrm{T}}{\partial \mathrm{x}}\right)_{2}+\frac{\Delta \mathrm{x}^{2}}{4 \cdot 2 !}\left(\frac{\partial^{2} \mathrm{~T}}{\partial \mathrm{x}^{2}}\right)_{2}-\frac{\Delta \mathrm{x}^{3}}{8 \cdot 3 !}\left(\frac{\partial^{3} \mathrm{~T}}{\partial \mathrm{x}^{3}}\right)_{2}+\cdots \\
\mathrm{T}_{3}=\mathrm{T}_{2}+\Delta \mathrm{x}\left(\frac{\partial \mathrm{T}}{\partial \mathrm{x}}\right)_{2}+\frac{\Delta \mathrm{x}^{2}}{2 !}\left(\frac{\partial^{2} \mathrm{~T}}{\partial \mathrm{x}^{2}}\right)_{2}+\frac{\Delta \mathrm{x}^{3}}{3 !}\left(\frac{\partial^{3} \mathrm{~T}}{\partial \mathrm{x}^{3}}\right)_{2}+\cdots
\end{gathered}
$$

Combining these equations with equation 15 gives:

$$
\begin{gathered}
\left.\rho c\left(\frac{\partial T}{\partial t}\right)_{2}+\frac{\Delta t}{2}\left(\frac{\partial^{2} T}{\partial t^{2}}\right)_{2}+\ldots\right)= \\
k\left(\frac{3}{4}\left(\frac{\partial^{2} T}{\partial x^{2}}\right)_{2}+\frac{1}{16} \Delta x\left(\frac{\partial^{3} T}{\partial x^{3}}\right)_{2},\right.
\end{gathered}
$$

As $\Delta \mathrm{x}$ and $\Delta t$ approach zero, this becomes:

$$
\left(\frac{\partial T}{\partial t}\right)_{2}=\frac{3}{4} \alpha\left(\frac{\partial^{2} T}{\partial x^{2}}\right)_{2}
$$


which is not equation 2. Thus equation 11 is inconsistent with equation 2 and DLM solutions will never converge to the correct solution. Allen 9 also noticed that DLM leads to equation 20 at node 2 .

The source of the DLM inconsistency is that too much mass has been assigned to node 2 . Once a nodal arrangement (grid system) has been selected, consistency requirements dictate that mass cannot be assigned indiscriminantly to each node. As an illustration, one can consider the three successive unevenly spaced $(R \neq 1)$ nodes in the one-dimensional arrangement shown in Figure 4. According to the usual nodal methods, the heat balance equation states that the conduction from node 1 to node 2 equals the conduction from node 2 to node 3 plus the internal energy stored at node 2 , i.e.:

$$
\frac{k}{R \Delta x}\left(T_{1}-T_{2}\right)=\rho c V_{2} \frac{\left(T_{2}^{+}-T_{2}\right)}{\Delta t}+\frac{k}{\Delta x} \quad\left(T_{2}-T_{3}\right)
$$

where $V_{2}$ is node 2 's volume. When this is done each node is often regarded as a point mass. In order to determine what $V_{2}$ has to be for consistency, $\mathrm{T}_{1}, \mathrm{~T}_{2}^{+}$, and $\mathrm{T}_{3}$ are expanded in Taylor series about $\mathrm{T}_{2}$. $\mathrm{T}_{2}^{+}$and $\mathrm{T}_{3}$ can be found from equations 16 and $18 . \mathrm{T}_{1}$ is:

$$
\mathrm{T}_{1}=\mathrm{T}_{2}-R \Delta \mathrm{x}\left(\frac{\partial \mathrm{T}}{\partial \mathrm{x}}\right)_{2}+R^{2} \frac{\Delta \mathrm{x}^{2}}{2 !}\left(\frac{\partial^{2} \mathrm{~T}}{\partial \mathrm{x}^{2}}\right)_{2}-R^{3} \frac{\Delta \mathrm{x}^{3}}{3 !}\left(\frac{\partial^{3} \mathrm{~T}}{\partial \mathrm{x}^{3}}\right)_{2}+\cdots
$$

Combining equations 16,18 , and 22 with equation 21 gives:

$$
\begin{gathered}
\left.\rho c v_{2}\left(\frac{\partial T}{\partial t}\right)_{2}+\frac{\Delta t}{2}\left(\frac{\partial^{2} T}{\partial t^{2}}\right)_{2}+\ldots\right)= \\
k\left(\frac{1}{2}(\beta+1) \Delta x\left(\frac{\partial^{2} T}{\partial x^{2}}\right)_{2}+\frac{1}{6}\left(1-\beta^{2}\right) \Delta x^{2}\left(\frac{\partial^{3} T}{\partial x^{3}}\right)_{2}+\ldots\right)
\end{gathered}
$$

Neglecting $0(\Delta t)$ and $0\left(\Delta x^{2}\right)$ terms leaves:

$$
\rho_{c}\left(\frac{\partial T}{\partial t}\right)_{2}=k \frac{\beta+1}{2} \Delta x\left(\frac{\partial^{2} T}{\partial x^{2}}\right)_{2}
$$

For consistency, $\mathrm{V}_{2}$ must be:

$$
v_{2}=\frac{\beta+1}{2} \Delta x
$$




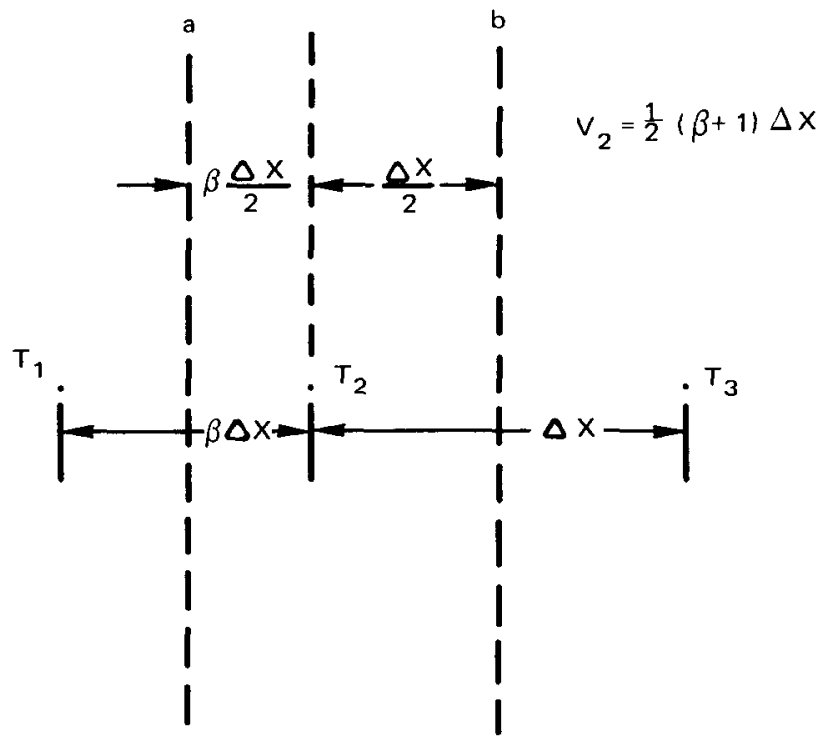

(U) Fig. 4 NODAL VOLUME ARRANGEMENT (U) 
The analysis leading to this equation can be easily generalized to three dimensions and to variable thermal property systems (e.g., see Appendix A).

In light of equation 25 , the best way to treat the nodal energy balance is not to think of node 2 in Figure 4 as a point mass but as a control volume with control surfaces $a$ and $b$ shown in Figure 4. Then the energy balance would be stated as: the conduction across surface $a=$ the energy stored within the control volume plus the conduction across surface b.

Clearly equation 11 violates equation 25 . The mass assigned to node 2 in Figure 3 should be $\frac{3}{4} \rho \Delta x$ and not $o \Delta x$. Thus equation 11 should be rewritten as:

$$
\frac{2 k}{\Delta x}\left(T_{1}-T_{2}\right)=\frac{3}{4} \frac{\rho c \Delta x}{\Delta t}\left(T_{2}^{+}-T_{2}\right)+\frac{k}{\Delta x}\left(T_{2}-T_{3}\right)
$$

Equation 10 is also in error because the conductive term on the right side of that equation is the conduction across the control surface halfway between nodes 1 and 2 in Figure 3 . Therefore equation 10 should also include a storage term with nodal mass $\frac{1}{4} \rho \Delta x$ to give:

$$
h\left(T_{\infty}-T_{1}\right)=\frac{1}{4} \rho c \Delta x\left(T_{1}^{+}-T_{1}\right)+\frac{2 k}{\Delta x}\left(T_{1}-T_{2}\right)
$$

Equations 26 and 27, although superior to equations 10 and 11 , negate the advantages of DLM over SVE since they also comprise a surface volume element treatment. The goal of writing a surface energy balance which does not adversely affect numerically stable time steps for high surface coefficients remains a desirable one, but it has to be done correctly. It can be done by improving the estimate of the wall temperature gradient.

Method III, Improved Wall Conduction Estimation (IWC):

This method treats equation 3 directly by using an estimate of the surface temperature gradient which has the same order of accuracy as temperature gradient estimates used elsewhere in the system. This allows a heat balance on the surface with a zero volume control volume. The type of grid system used is that shown in Figure 2 .

For interior nodes in this system, the conduction across any control surface is always estimated in terms of the two nodal temperatures on either side of that control surface. For the control surface between nodes 1 and 2 this is

$$
\frac{\mathrm{k}}{\Delta \mathrm{x}}\left(\mathrm{T}_{1}-\mathrm{T}_{2}\right)
$$


which is an estimate of $-k \partial T / \partial x$ at a point halfway between nodes 1 and 2 (point " $1 \frac{1}{2}$ "). The error of the estimation can be determined by expanding $\mathrm{T}_{1}$ and $\mathrm{T}_{2}$ about $\mathrm{T}_{1 \frac{1}{2}}$ :

$$
\mathrm{T}_{1,2}=\mathrm{T}_{1 \frac{1}{2}} \pm \frac{\Delta \mathrm{x}}{2}\left(\frac{\partial \mathrm{T}}{\partial \mathrm{x}}\right)_{1 \frac{1}{2}}+\frac{\Delta \mathrm{x}^{2}}{4 \cdot 2 !}\left(\frac{\partial^{2} \mathrm{~T}}{\partial \mathrm{x}^{2}}\right)_{1 \frac{1}{2}} \pm\left(\frac{\partial^{3} \mathrm{~T}}{\partial \mathrm{x}^{3}}\right)_{1 \frac{1}{2}} \frac{\Delta \mathrm{x}^{3}}{8 \cdot 3 !}+\ldots
$$

to obtain:

$$
\frac{k}{\Delta x}\left(T_{1}-T_{2}\right)=-k\left(\frac{\partial T}{\partial x}\right)_{1 \frac{3}{2}}-\frac{1}{4 \cdot 3 !} \Delta x^{2}\left(\frac{\partial^{3} T}{\partial x^{3}}\right)_{1 \frac{1}{2}}
$$

This shows that the expression 28 estimates the thermal conduction across the control surface $1 \frac{1}{2}$ to $0\left(\Delta x^{2}\right)$. Therefore any FDA of the surface temperature gradient in equation 3 should also be accurate to $0\left(\Delta x^{2}\right)$. If this can be done, there is no need to consider explicitly the internal energy storage of the half volume element next to the surface since the temperature gradient at the surface would be known as accurately as temperature gradients are known elsewhere in the system. This would represent an energy balance on a control volume with no volume at the surface. Expanding $\mathrm{T}_{2}$ and $\mathrm{T}_{3}$ about $\mathrm{T}_{1}$ gives

$$
\begin{aligned}
& \mathrm{T}_{2}=\mathrm{T}_{1}+\Delta \mathrm{x}\left(\frac{\partial \mathrm{T}}{\partial \mathrm{x}}\right)_{1}+\frac{\Delta \mathrm{x}^{2}}{2 !}\left(\frac{\partial^{2} \mathrm{~T}}{\partial \mathrm{x}^{2}}\right)_{1}+\frac{\Delta \mathrm{x}^{3}}{3 !}\left(\frac{\partial^{3} \mathrm{~T}}{\partial \mathrm{x}^{3}}\right)_{1}+\cdots \\
& \mathrm{T}_{3}=\mathrm{T}_{1}+2 \Delta \mathrm{x}\left(\frac{\partial \mathrm{T}}{\partial \mathrm{x}}\right)_{1}+\frac{4 \Delta \mathrm{x}^{2}}{2 !}\left(\frac{\partial^{2} \mathrm{~T}}{\partial \mathrm{x}^{2}}\right)_{1}+\frac{8 \Delta \mathrm{x}^{3}}{3 !}\left(\frac{\partial^{3} \mathrm{~T}}{\partial \mathrm{x}^{3}}\right)_{1}+\cdots
\end{aligned}
$$

An $0\left(\Delta x^{2}\right)$ accurate estimate of $(\partial T / \partial x)_{1}$ can be obtained from these equations by eliminating $\left(\partial^{2} \mathrm{~T} / \partial \mathrm{x}^{2}\right)_{1}$ between them, leaving:

$$
\frac{\left(4 T_{2}-3 T_{1}-T_{3}\right)}{2 \Delta x}=\left(\frac{\partial T}{\partial x}\right)_{1}-\frac{4}{3 !} \Delta x^{2}\left(\frac{\partial^{3} T}{\partial x^{3}}\right)_{1}
$$

Combining equations 30 and 3 gives: 


$$
h\left(T_{\infty}-T_{1}\right)=\frac{k}{2 \Delta x} \quad\left(3 T_{1}+T_{3}-4 T_{2}\right)
$$

Solving for $\mathrm{T}_{1}$ :

$$
\mathrm{T}_{1}=\frac{\left(2 \mathrm{MT}_{\infty}+4 \mathrm{~T}_{2}-\mathrm{T}_{3}\right)}{3+2 \mathrm{M}}
$$

This method has been suggested by Carslaw and Jaeger. 10

With this method interior point temperatures can be obtained from equation 4 and equation 6 is the stability requirement. Thus IWC does not impair interior point stability at all and it allows for time steps which are $1 \frac{1}{2}$ times as large as the Dusinberre time step for a given $\Delta x$. See Appendix D for further discussion of IWC.

Equation 31 would also hold in a two or three-dimensional system as long as $x$ is measured normal to the heat transfer area. For uneven grid spacings, Taylor series methods can be used to provide replacements to equation 31 (See Appendix B). This may be necessary when devising node dropping schemes in ablation and melting problems.

A disadvantage that DLM and IWC have in common is that the surface temperature is ultimately treated as a boundary condition even though the true surface boundary condition is a heat flux condition. $\mathrm{T}_{1}$ is governed by the heat equation just as all the interior temperatures are but DLM and IWC do not attempt to incorporate equation 3 into an approximate solution of the differential equation for $T_{1}$. SVE does this but leads to small time steps. A method which also does this and has no surface stability restriction will be discussed next.

Method IV, The E1rod Method (EM):

This method, derived by E1rod, 11 is applicable to one-dimensional systems with constant thermal properties. Elrod considers a semiinfinite solid subject to the surface boundary condition in equation 3. Each time interval $[t, t+\Delta t]$ is treated separately so that the temperature distribution $T(x, t)$ is regarded as an initial condition and $i t$ is desired to find $T(x, t+\Delta t)$. Elrod obtains exact solutions for $T(x, t+\Delta t)$ but since $T(x, t)$ is known only at discrete points in a grid system similar to Figure 2, approximate solutions involving the "old" grid point temperatures are obtained. The method is applied only to points 1 and 2 in Figure 2 in order to extend the semi-infinite analysis to finite systems. Temperatures at points 3,4 , etc. are found from equation 4 . The end result is the following set of equations: 


$$
\begin{aligned}
& \mathrm{T}_{1}^{+}=\mathrm{A}_{1} \mathrm{~T}_{1}+\mathrm{B}_{1} \mathrm{~T}_{2}+\mathrm{C}_{1} \mathrm{~T}_{3}+\mathrm{D}_{1} \mathrm{~T}_{\infty}+\mathrm{E}_{1} \mathrm{~T}_{\infty}^{+} \\
& \mathrm{T}_{2}^{+}=\mathrm{A}_{2} \mathrm{~T}_{1}+\mathrm{B}_{2} \mathrm{~T}_{2}+\mathrm{C}_{2} \mathrm{~T}_{3}+\mathrm{D}_{2} \mathrm{~T}_{\infty}+\mathrm{E}_{2} \mathrm{~T}_{\infty}^{+} \\
& \mathrm{T}_{i}^{+}=(1-2 r) \mathrm{T}_{i}+\mathrm{r}\left(\mathrm{T}_{i+1}+\mathrm{T}_{i-1}\right)(i \geq 3)
\end{aligned}
$$

where :

$$
\mathrm{T}_{\infty}^{+}=\mathrm{T}_{\infty}(t+\Delta t)
$$

The coefficients $A_{i}, B_{i}, C_{i}, D_{i}$ and $E_{i}(i=1,2)$ depend on $r$ and $M$ and equations for them are given by Elrod. Interior point stability time steps are not affected by this method.

The drawbacks of this method are that it cannot be easily adapted to variable thermal property situations and it would have to be reworked for multi-dimensional situations and different boundary conditions, none of which are simple tasks. On the other hand, it always gives very accurate results for those situations where it is applicable.

\section{EXACT SOLUTIONS OF THE SLAB PROBLEM}

In order to have a standard for judging the numerical methods just discussed, it is desirable to have some exact solutions to the slab problem previously considered (i.e., Figure 1). Using Laplace transform methods discussed by Carslaw and Jaeger, 10 one can find that:

$$
\begin{gathered}
T=T_{0}+\left(T^{*}-T_{0}\right)\left(1-2 \sum_{n=1}^{\infty} C_{n}(x, t)\right. \\
\left.+2 \frac{\alpha}{L^{2}} \sum_{n=1}^{\infty} \int_{0}^{t} F(u) \mu \frac{2}{n} c_{n}(x, t-u) d u\right)
\end{gathered}
$$

where: 


$$
C_{n}(x, t)=\frac{\sin \mu_{n} \cos \left[\mu_{n}(1-x / L)\right]}{\mu_{n}+\sin \mu_{n} \cos \mu_{n}} \exp \left(\frac{-\mu_{n}^{2} \alpha t}{L^{2}}\right)
$$

and $\mu_{n}(n=1,2 \ldots)$ are the roots of the equation:

$$
\frac{\mathrm{hL}}{\mathrm{k}} \cos \mu_{\mathrm{n}}=\mu_{\mathrm{n}} \sin \mu_{\mathrm{n}}
$$

In the present study, $F(t)$ was chosen to be $F(t)=$ At for most of the cases studied, although $F(t)=A$ sin $\omega t$ was also used in a few instances. The explicit solutions for the two choices of $F(t)$ are written out in Appendix $C$.

\section{COMPARISONS OF NUMERICAL AND EXACT SOLUTIONS}

Numerical solutions to the slab problem were obtained for all four methods discussed and appropriate analytical solutions were also obtained. In one series of calculations (Series 1), the following parameters were used: $\mathrm{h}=1660 \mathrm{Btu} /\left(\mathrm{hr}-\mathrm{ft} \mathrm{t}^{2} \mathrm{o}^{\circ} \mathrm{F}\right), \mathrm{k}=1.5 \mathrm{Btu} /\left(\mathrm{hr}-\mathrm{ft}-{ }^{\circ} \mathrm{F}\right)$, and $\alpha=1.6667 \times 10^{-5} \mathrm{ft}^{2} / \mathrm{sec}$. This results in a Biot number (hL/k) of 46.1111 and an inverse time factor $\alpha / \mathrm{L}^{2}$ of $9.6 \times 10^{-3}(\mathrm{sec})^{-1}$. In the other series of calculations (Series 2), $h=2400 \mathrm{Btu} /\left(\mathrm{hr}-\mathrm{ft}^{2}{ }^{\circ} \mathrm{F}\right)$, $\mathrm{k}=1.0 \mathrm{Btu} /\left(\mathrm{hr}-\mathrm{ft}-{ }^{\circ} \mathrm{F}\right)$, and $\alpha=1.111 \times 10^{-5} \mathrm{ft} / 2 / \mathrm{sec}$, resulting in a Biot number of 100 and $\alpha / \mathrm{L}^{2}=6.4 \times 10^{-3}(\mathrm{sec})^{-1}$. As mentioned earlier, the solid material's thermal properties are typical of T-50 composite material and the values of $h, T_{o}$ and $T_{\infty}$ are chosen to provide heating rates typical of those undergone by T-50 during the reentry of General Electric MHW/HSA. In Series I both the linear and sinusoidal bath temperatures mentioned in the previous section were used while in Series 2 only the linear case was studied. $\mathrm{T}^{*}$ was always $2700^{\circ} \mathrm{F}$ and $\mathrm{T}_{O}$ was always $500^{\circ} \mathrm{F}$. For the linear bath, $\mathrm{A}=614.29^{\circ} \mathrm{F} / \mathrm{sec}$ was used (causing the bath temperature to rise from $2700^{\circ} \mathrm{F}$ to $7000^{\circ} \mathrm{F}$ in seven seconds) while for the sinusoidal bath $\mathrm{A}=2000^{\circ} \mathrm{F}$ was used with $\omega=2 \pi / 10$ radians $/ \mathrm{sec}$.

Figures 5 through 8 summarize the computational results for the 1 inear bath in terms of the percentage errors incurred, where the error, $\epsilon$, is:

$$
\varepsilon=100 \frac{\left(T_{N}-T_{E}\right)}{\left(T_{E}-T_{O}\right)}
$$

$\mathrm{T}_{\mathrm{N}}$ is the numerically determined solution and $\mathrm{T}_{\mathrm{E}}$ is the exact solution. For these figures, an 11 node grid system for the half slab was used 


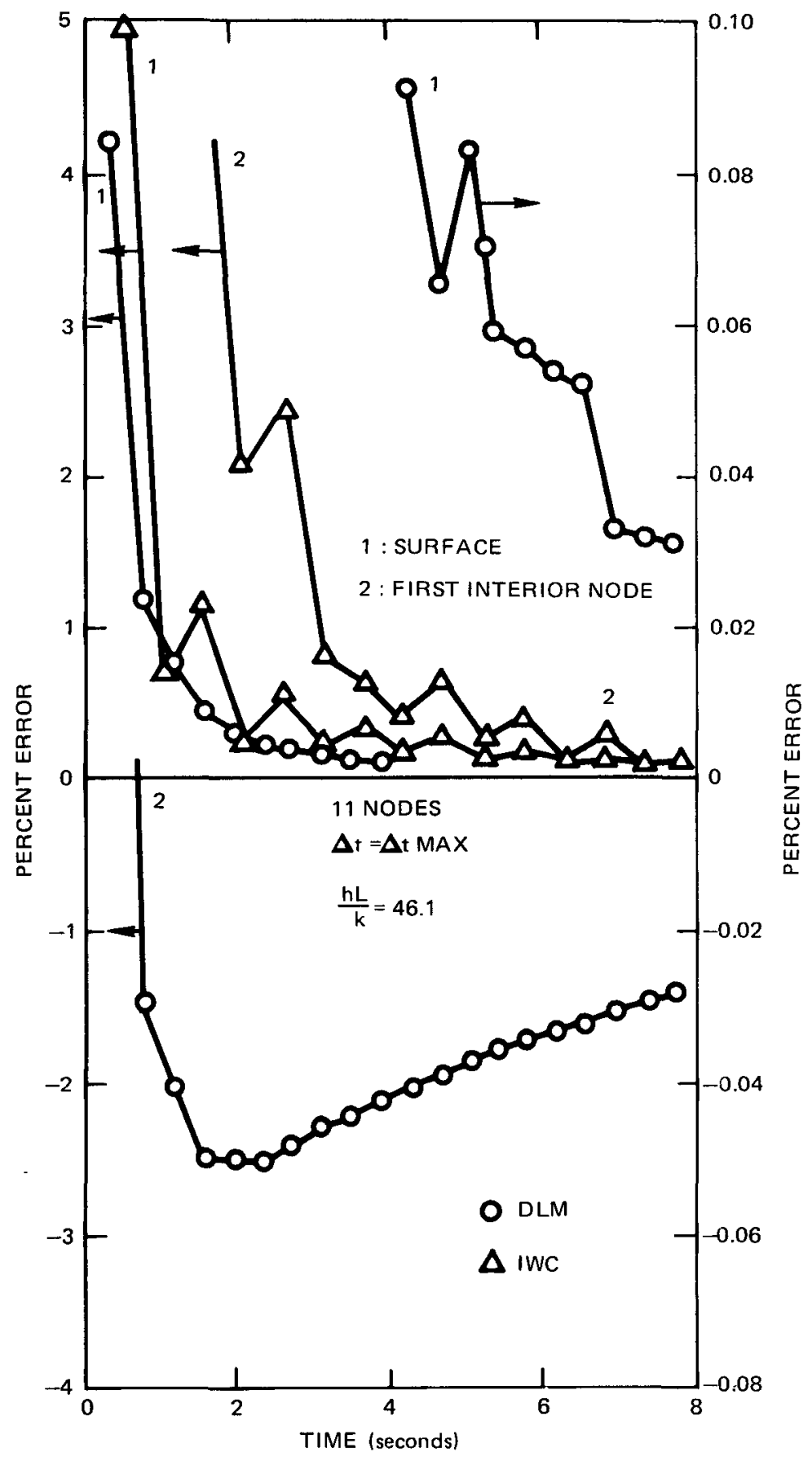

(U) Fig. 5 COMPUTATIONAL ERRORS $F(t)=614.29 t(U)$ 


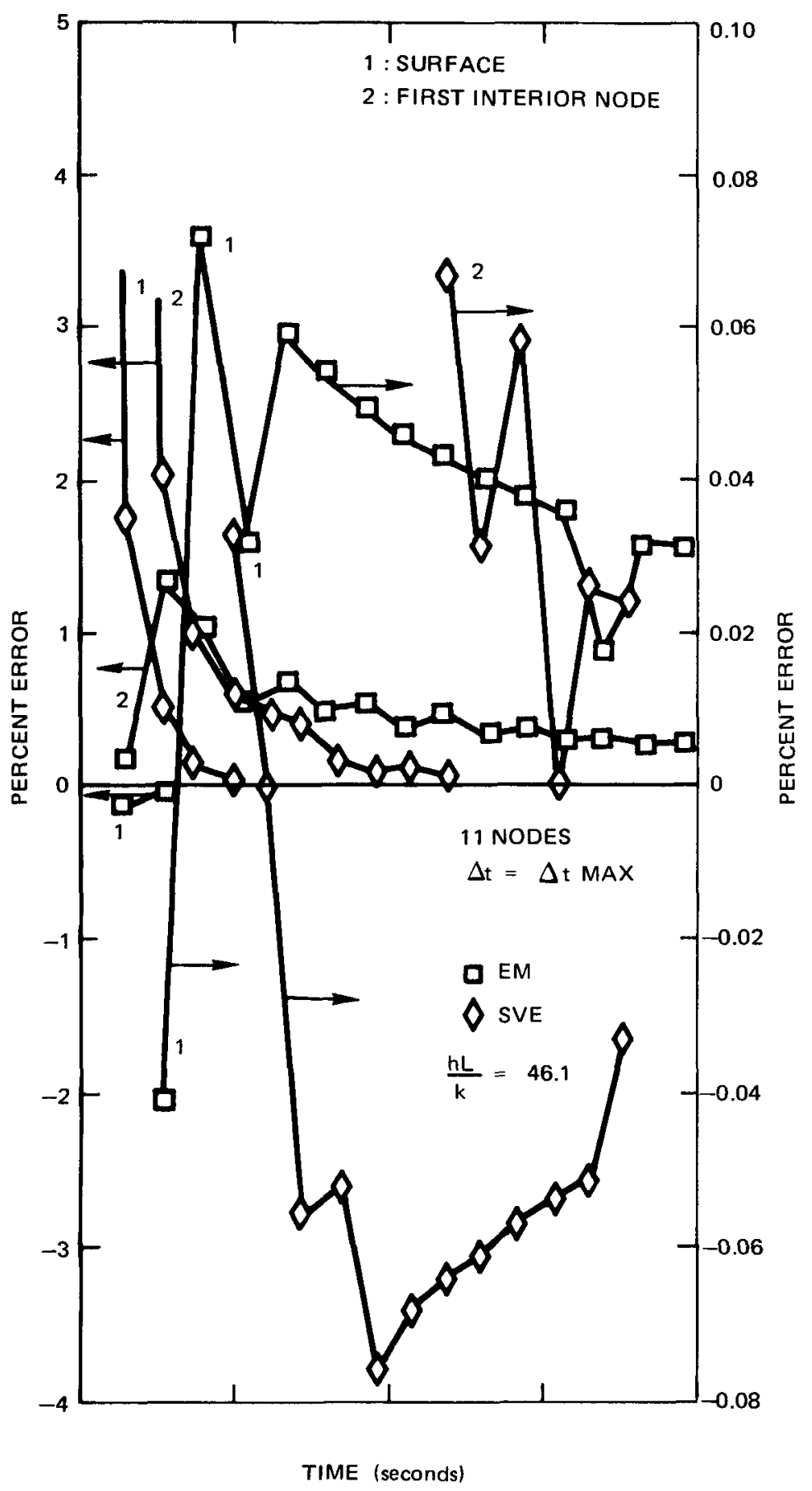

(U) Fig. 6 COMPUTATIONAL ERRORS $F(t)=614.29 \mathrm{t}(\mathrm{U})$ 


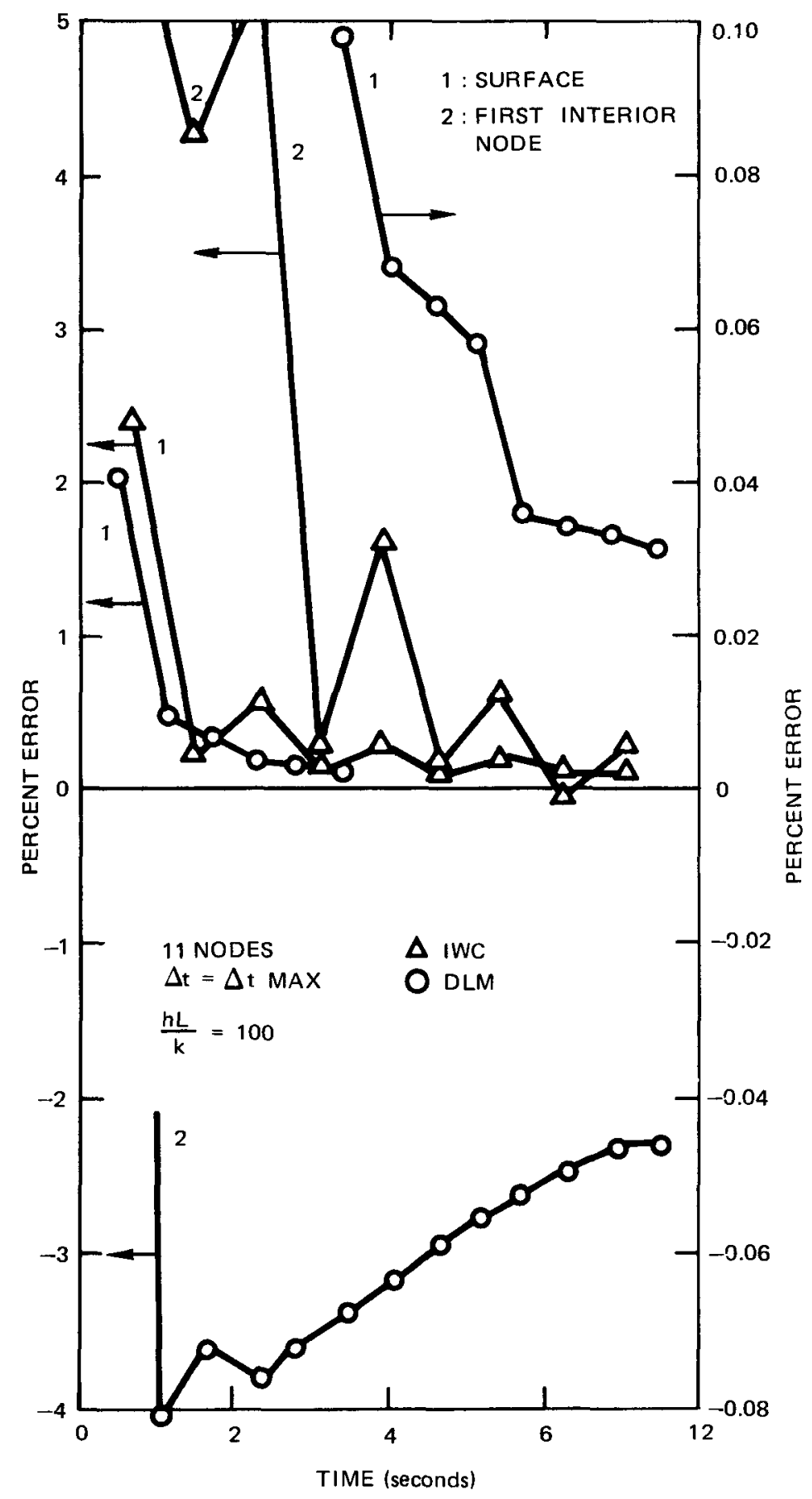

(U) Fig. 7 COMPUTATIONAL ERRORS $F(t)=614.29 t(U)$ 


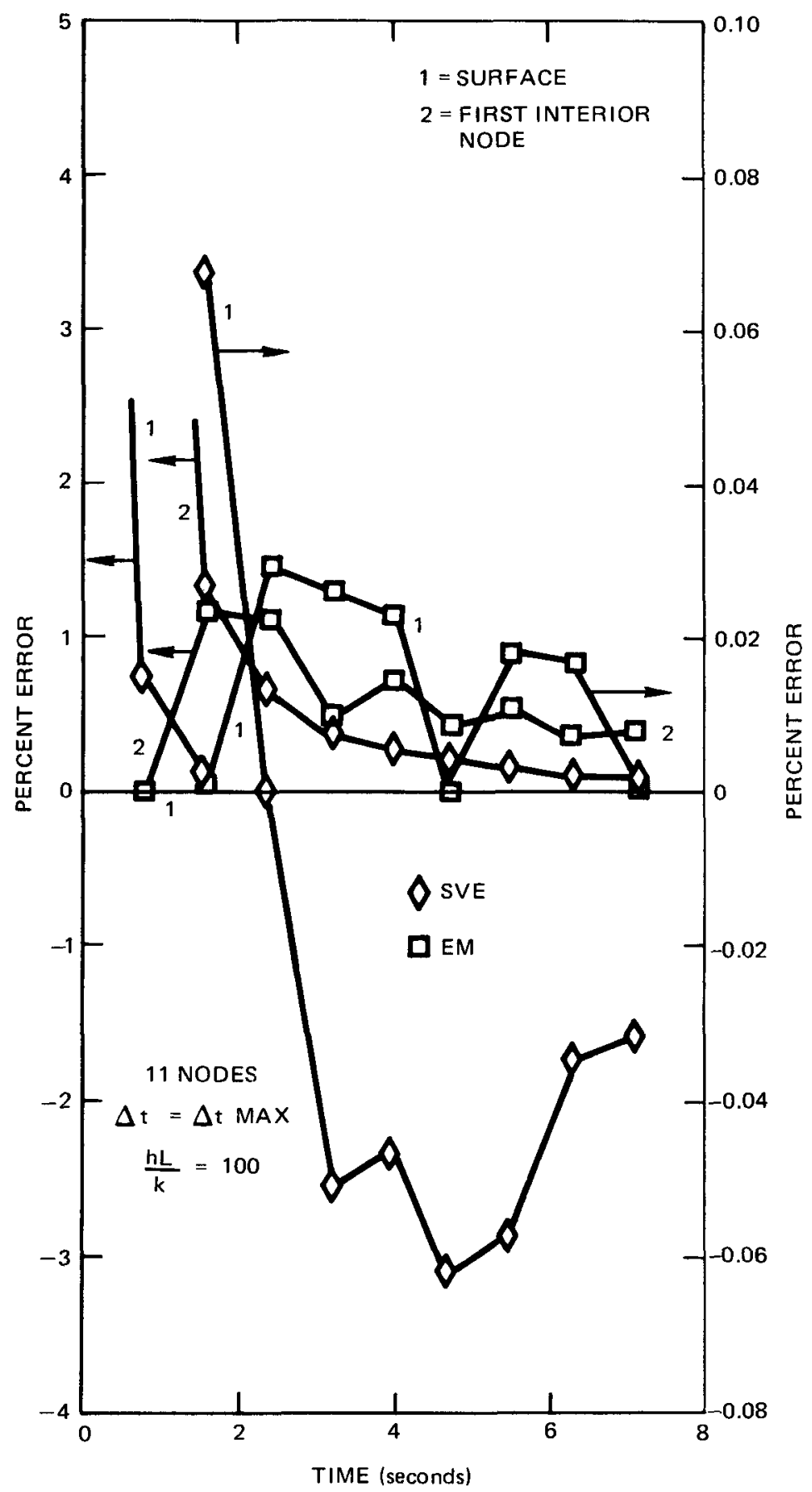

(U) Fig. 8 COMPUTATIONAL ERRORS $F(t)=614.29$ t (U) 
and the maximum allowable time step for each numerical method was used. Results are plotted for the surface node (curves marled 1) and the first node adjacent to the surface (curves marked 2). Table 1 summarizes the values of $\Delta t$ and $\Delta x$ used.

As Figures 6 and 8 show, EM is the most successful of the four methods for all of the computation times. The other three methods overestimate early time temperatures considerably. Those errors which would not fit on the graphs are listed in Table 2 .

For SVE, DLM, and IWC small time errors are always large but once initial transient effects dampen, the errors incurred by all four methods fall rapidly to within $1 \%$ in magnitude, except for the first interior node DLM computation in which the temperature is always underestimated by a nearly constant amount even after initial transient effects have died out. A comparison of Figures 5 and 7 shows that this situation worsens with larger values of $\mathrm{hL} / \mathrm{k}$. As pointed out earlier, this happens because DLM assigns to much mass to the first interior node. Nodes farther away from the surface also show low temperatures for DLM while for the other three methods, agreement with the exact solution appears to be quite good. See Figure 9 .

Experimentation with the sinusoidal bath showed that DLM underestimates interior node temperatures which increase in time but overestimates those which decrease in time. Smith ${ }^{7}$ advances the possibility that inconsistent FDA's might lead to errors proportional to $t \mathrm{oT} / \partial \mathrm{t}$ which, for a sinusoidal bath, would grow indefinitely in time. Fortunately, errors incurred by DLM with the sinusoidal bath remained bounded.

There does not appear to be any "cheap" way to reduce the large small time errors incurred by DLM, IWC, and SVE. Concentrating on Series 2 calculations with a linear bath for purposes of discussion, Figures 9 and 10 show that the surface temperature rises fastest in time during the first 0.1 seconds after the slab is exposed to the bath. The maximum time steps used in the 11 node systems skip over most (SVE) or all (DLM, IWC, EM) of this initial period. Furthermore, very steep temperature gradients exist near the suriace for early times and these are not well resolved by an eleven node system. It is therefore not surprising that SVE, DLM, and IWC should give erroneous results for small times. Only EM, which makes use of exact solutions of the heat equation, gives good sma11 time results.

The easiest way to try to improve early time results is to reduce the time step while retaining the same spatial grid system. In Figure 10, the DLM, IWC, and EM time steps were reduced to 0.1 seconds in the 11 node system. Some improvement of the IWC results is evident at both surface and interior nodes. DLM surface results are also improved somewhat but interior node temperatures are still being underestimated. EM results actually became worse, overestimating temperatures everywhere, which is probably due to the 
Table 1

Spatial Grid Sizes and Maximum Time Steps

(11 Node System, $L=\frac{1}{2} "=0.04167^{\prime}$ )

\begin{tabular}{|c|c|c|c|}
\hline Me thod & $\Delta \mathrm{x} / \mathrm{L}$ & $\begin{array}{c}\text { Series } 1 \\
\operatorname{Max} \cdot \Delta t(\mathrm{sec})\end{array}$ & $\begin{array}{c}\text { Series } 2 \\
\operatorname{Max} \cdot \Delta t(\sec )\end{array}$ \\
\hline SVE & 0.1 & 0.0928 & 0.0710 \\
\hline DLM & 0.1053 & 0.3847 & 0.5771 \\
\hline IWC & 0.1 & 0.5208 & 0.7812 \\
\hline EM & 0.1 & 0.5208 & 0.7812 \\
\hline
\end{tabular}


THE JOHNS MOPKINS UNIVERSITY APPLIED PHYSICS LABORATORY Silver spring maryland
Page 22.

Table 2

Errors Not Plotted in Figures

5 Through 8

$\begin{array}{ccccc}\text { Figure } & \text { Method } & \text { Curve } & \text { Time (sec) } & \text { \% Error } \\ 5 & \text { DLM } & 2 & 0.385 & 11.004 \\ 5 & \text { IWC } & 2 & 0.521 & 52.015 \\ 5 & \text { IWC } & 2 & 1.042 & 8.159 \\ 5 & \text { IWC } & 2 & 1.562 & 6.756 \\ 6 & \text { SVE } & 1 & 0.093 & 22.508 \\ 6 & \text { SVE } & 2 & 0.093 & -100 \\ 6 & \text { SVE } & 2 & 0.557 & 6.507 \\ 7 & \text { DLM } & 2 & 0.557 & 9.123 \\ 7 & \text { IWC } & 2 & 0.781 & 46.293 \\ 7 & \text { IWC } & 2 & 2.344 & 5.292 \\ 8 & \text { SVE } & 2 & 0.781 & 6.354\end{array}$




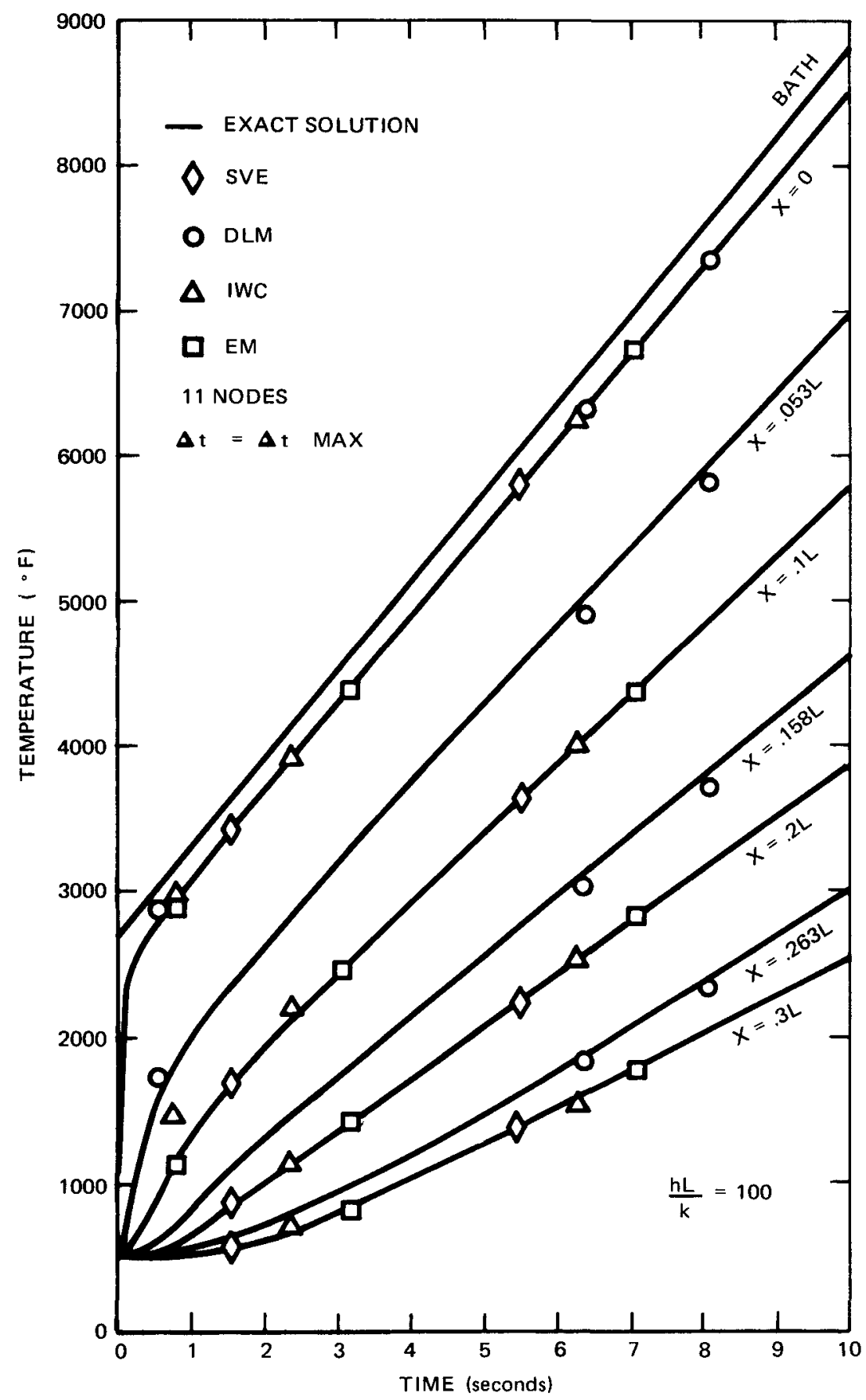

(U) Fig. 9 COMPARISON OF SURFACE TEMPERATURE METHODS $F(t)=614.29 t(U)$ 


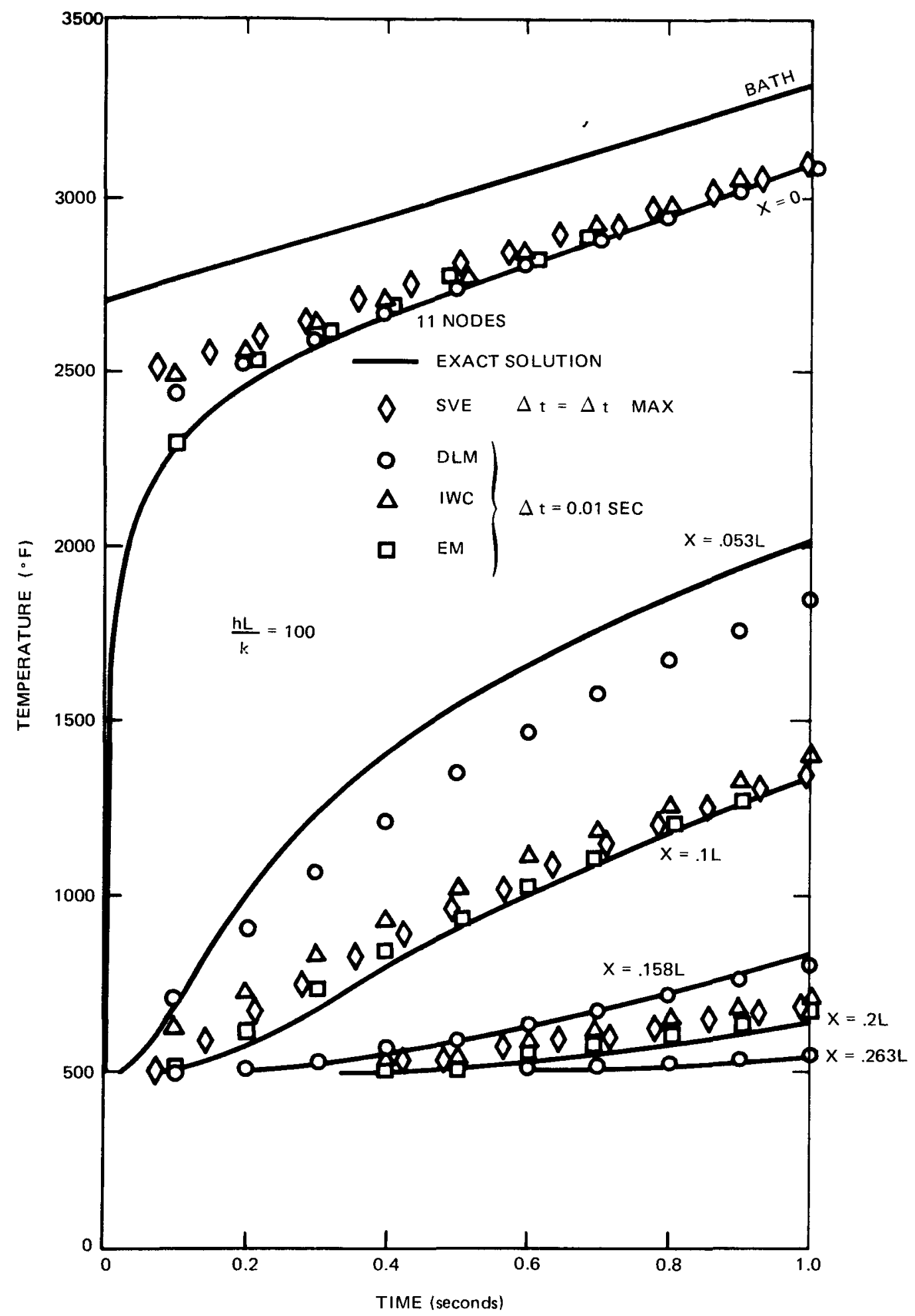

(U) Fig. 10 COMPARISON OF SURFACE TEMPERATURE METHODS $F(t)=614.29 \mathrm{t}(\mathrm{U})$ 
poor resolution of steep small time temperature gradients. As Figure 11 shows, the situation worsens for a 11 four methods when the time step is dropped to 0.01 seconds in the 11 node system. SVE now underestimates surface temperatures considerably while EM generally overestimates them. IWC and DLM still overestimate the surface temperature during most of the time period considered. As a general rule, it appears that for a given $\Delta x$ the best computational results can be obtained from a given explicit method by using its maximum a llowable $\Delta t$. If a reduction in $\Delta t$ is desired, a corresponding reduction in $\Delta x$ should also be made.

At this point it is obvious that the only practical alternative to DLM is IWC. Therefore further discussion will concentrate on these two methods.

For the material and heating rates being considered here, user experience with the SHTP ${ }^{12}$ indicates that grid spacings which result in time steps in the neighborhood of 0.1 seconds give satisfactory computational results which are not prohibitively expensive. If the half slab being considered here is divided into 25 nodes, the maximum allowable time steps for the IWC and DLM methods are 0.1356 seconds and 0.0943 seconds, respectively. Results of Series 2 computations for a linear bath temperature are shown in Figures 12 and 13. These figures show a considerable reduction in error in comparison to the 11 node model. Small time errors are still quite large for both IWC and DLM but after about one second IWC errors for both the surface and first interior nodes fall rapidly toward zero as does the DLM surface error. However the first interior node DLM error again approaches a constant negative non-zero number. Al1 errors for the 25 node models are smaller than those for the 11 node models. Actual computer time needed to perform the IWC computations summarized in Figure 13 is about $12 \%$ longer than that needed to take the same number of time steps for the DLM computations. This is more than compensated for by the $43 \%$ longer time covered by the IWC computations ( $13.56 \mathrm{sec}$. vs $9.43 \mathrm{sec}$.$) .$

Further refinement of the spatial mesh to 81 nodes gave vastly improved small time results for both inethods and the error caused by the DLM inconsistency seemed to have almost vanished. Both methods gave results which agreed very well with the corresponding exact solutions and the apparent percentage error, based on computer printouts which listed two digits after the decimal point in temperature listings, was often zero. The only real advantage of IWC in this case is that a larger time step ( 1.48 times as large as DIM) could be used. This behavior was exhibited in Series 2 calculations where $h$ was varied to give Biot numbers of $1,10,100$, and 1000 . For a Biot number of 1000 , IWC errors were somewhat smaller than DLM errors but both were very small. 


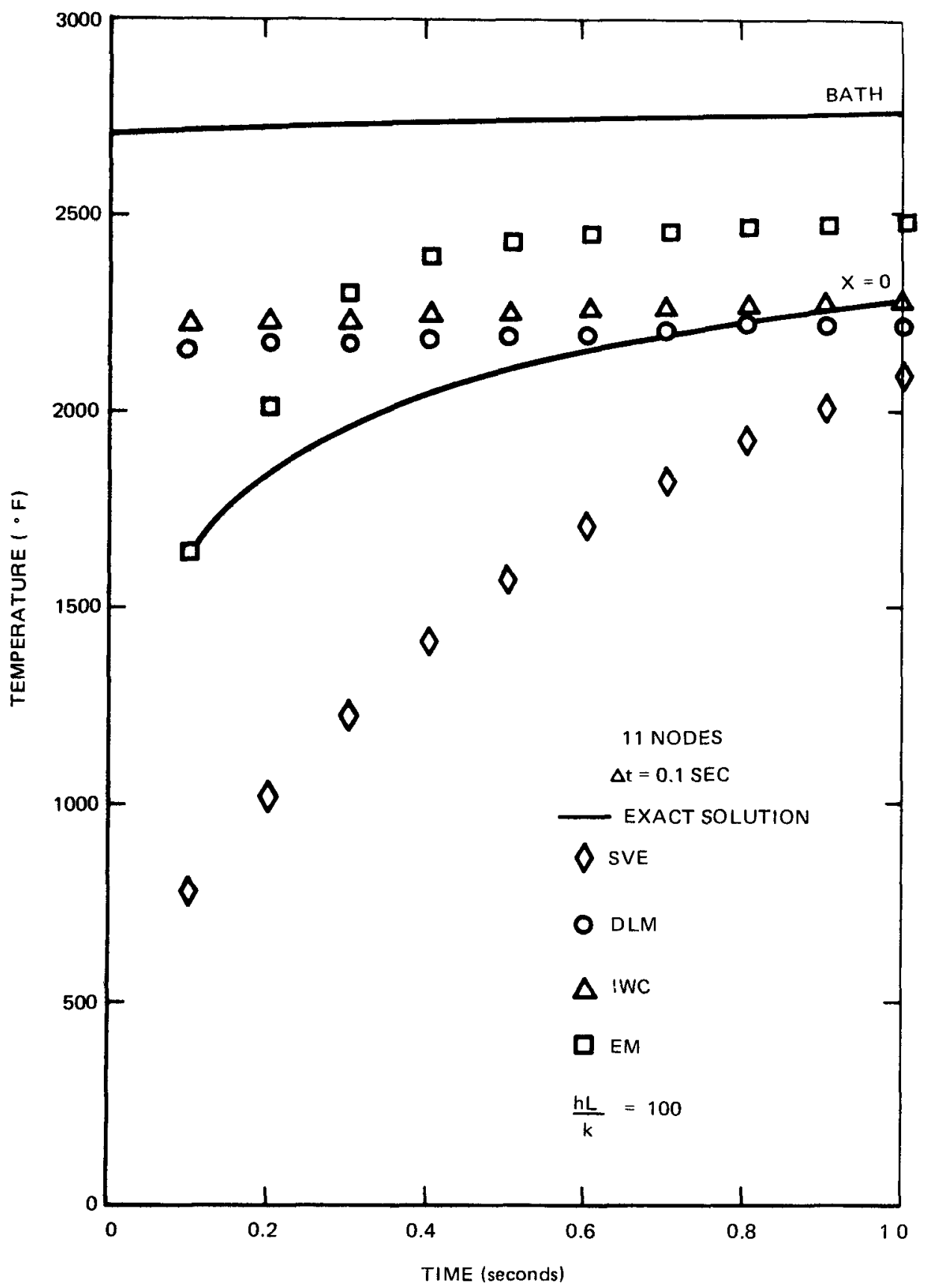

(U) Fig. 11 EARLY TIME SURFACE TEMPERATURES $F(t)=614.29 \mathrm{t}(\mathrm{U})$ 


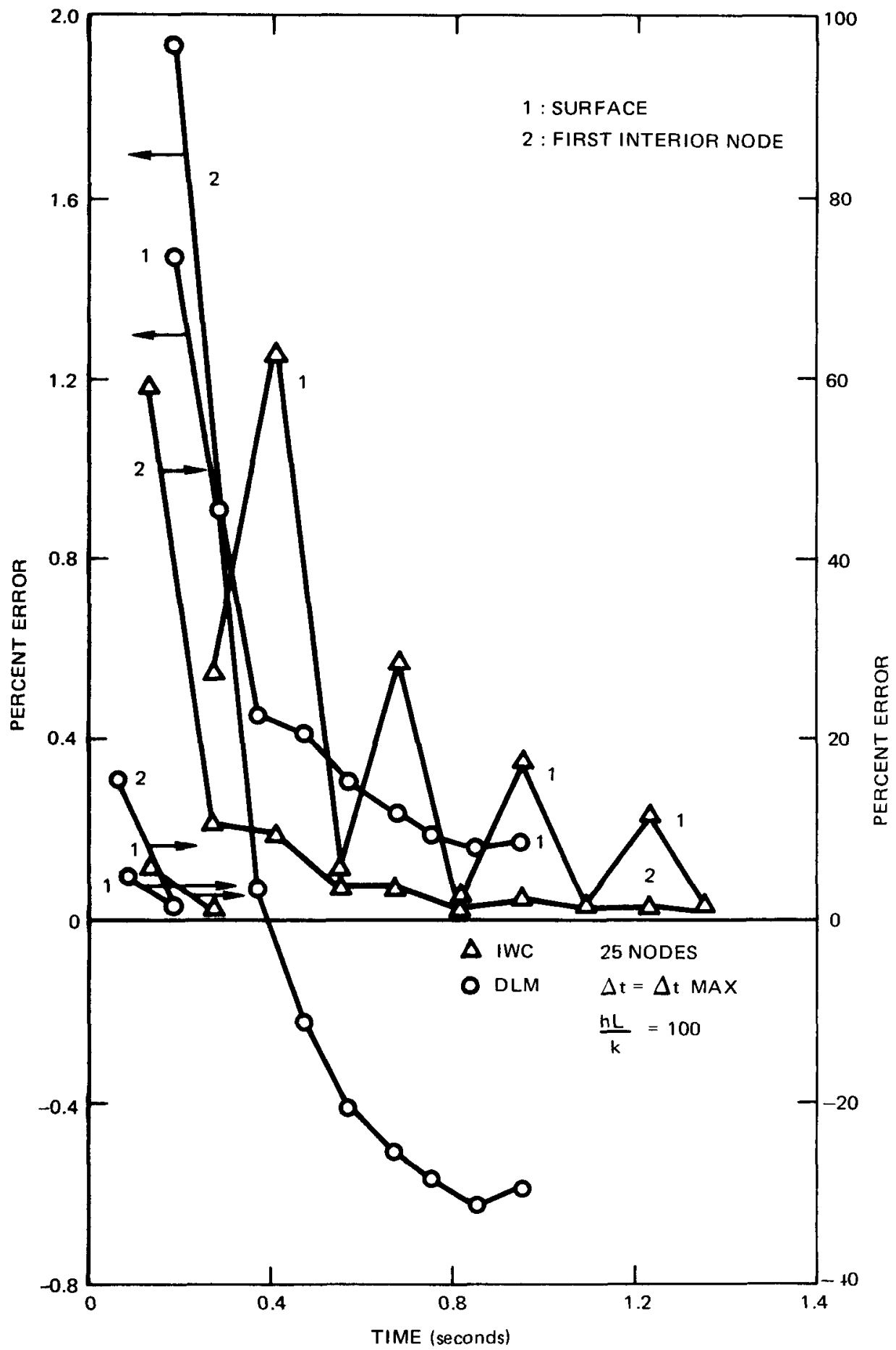

(U) Fig. 12 COMPUTATIONAL ERRORS $F(t)=614.29 t(U)$ 


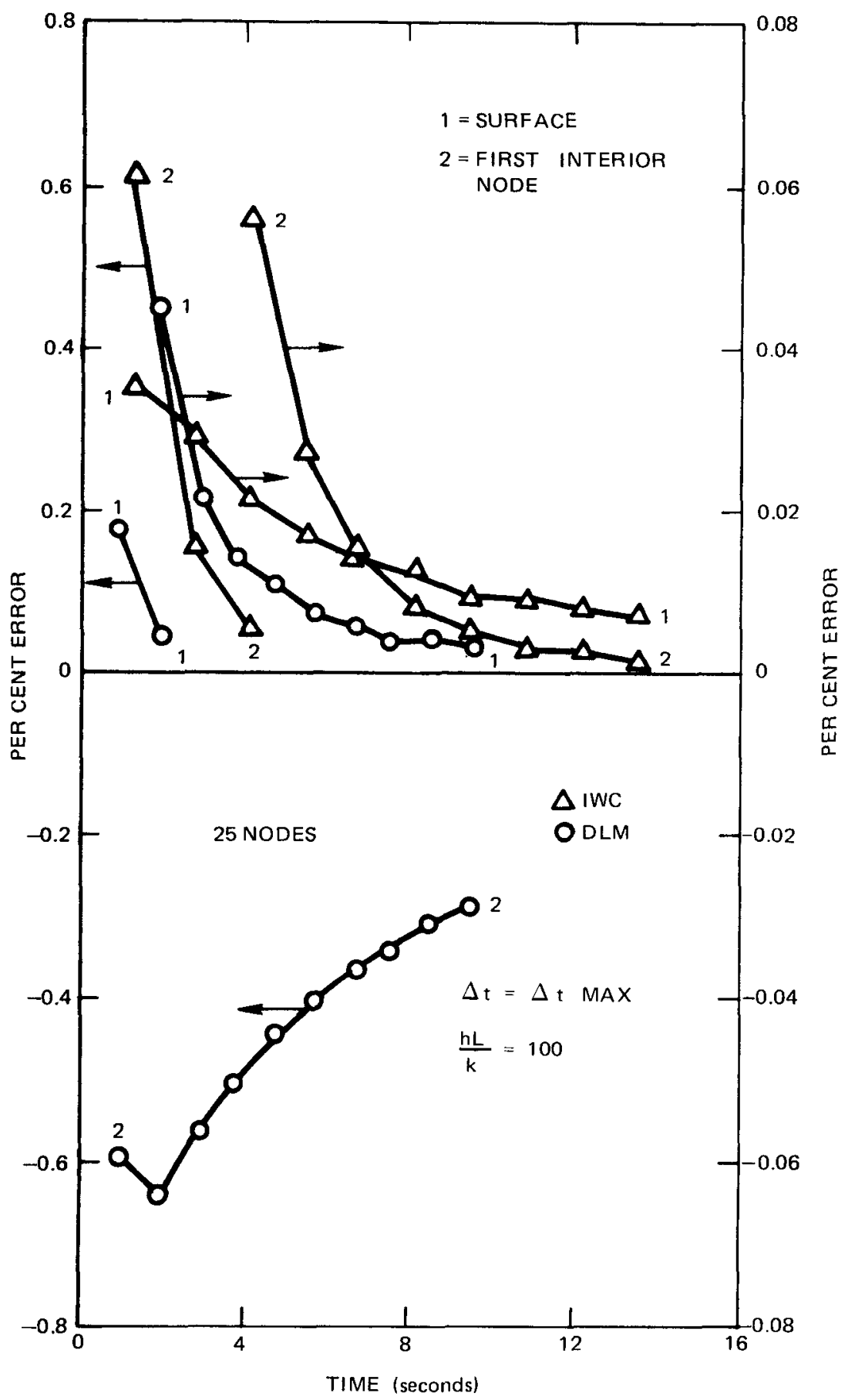

(U) Fig. 13 COMPUTATIONAL ERRORS $F(t)=614.29 \mathrm{t}(U)$ 
For explicit schemes such as those being considered here, it appears that the best way to obtain good small time results is to refine the spatial mesh, at least near the surface where temperature gradients are very steep. During a short initial time period, the slab could be treated as a semi-infinite solid. Then, as soon as the early surface and near-surface temperatures have been determined accurately up to a point in time when temperatures are not changing so rapidly, some of the final temperatures from this run could be used as initial data for advancing the calculation in a coarser grid system. This is admittedly awkward but poor surface and nearsurface temperatures at the first few time levels are a consequence of using explicit methods. For the methods considered here, at $t=\Delta t$, SVE shows a response only in the surface node while DLM, IWC, and EM a 11 show responses only in the surface and first interior nodes. According to equation 37, a 11 the other nodes will have errors of $-100 \%$. In reality several other nodes should also have shown some response. The only way to make this happen at time $t=L t$ with a numerical model is to use implicit or mixed explicit - implicit methods which pose computer storage problems as a trade off for increased accuracy

\section{CONCLUSIONS}

Of the four numerical methods used in this study, the Elrod method (EM) is by far the most accurate. However, EM is derived under the assumption of constant slab thermal properties and surface coefficient in a one-dimensional system. Generalizing EM to two and threedimensional systems with constant thermal properties would be fairly straight-forward (although tedious) but with variable the rmal properties, the situation would be considerably complicated mathematically requiring involved perturbation solutions of questionable value. In short, EM is not easily adaptable to the SHTP.

The surface volume element method (SVE) is unacceptable for the we11 known reason that it requires prohibitively small time steps for high surface coefficients.

This leaves the improved wall conduction estimation method (IWC) as the only usable method which can be proposed as a possible replacement of the Dusinberre lumping method (DLM) in the SHTP. As Figures 5 and 7 show, DLM holds some advantage over IWC in terms of surface temperature errors but IWC is vastly superior to DLM in terms of errors incurred at interior nodes. Furthermore, IWC allows for larger stable time steps than DLM. Small time errors generated by IWC can be resolved by using more accurate nodal arrangements for those time periods in which temperatures change rapidly. Since IWC nearly always overestimates temperatures somewhat, it has an additional advantage of giving "conservative" results, in terms of temperature but perhaps not in terms of thermal stress. 
The incorporation of IWC into the SHTP should be fairly straightforward. The major difference between it and DLM is that it uses three temperatures instead of two to estimate the surface temperature gradient. A more general equation than equation 30 for this gradient is given in Appendix B.

In the future, perhaps a study should be conducted to evaluate the use of implicit methods for getting better small time temperature responses.

As a final recommendation, users of the SHTP should check their nodal energy balances for consistency with the heat equation. Correct solutions require consistency as well as stability.

\section{REFERENCES}

1. Property tables supplied to APL by General Electric for MHW/HSA nuclear safety analysis.

2. Gebhart, B., Heat Transfer, McGraw-Hill Book Company, Inc., New York, 1961 .

3. Allen, R. W., Surface Temperature by the Finite Difference Method, APL/JHU EM-4163, Feb. 6, 1968.

4. Kreith, F., Principles of Heat Transfer, International Text Book Co., Scranton, Pa., 1966.

5. Allen, R.W., and Suess, R.P., A Furtran Computer Program for the Solution of Multi-Dimensional, Transient Ablation Problems, APL/JHU TG-648, Feb. 1965 .

6. Dusinberre, G., Heat Transfer Calculations by Finite Differences, International Text Book Co., Scranton, Pa., 1961.

7. Allen, R.W. and Newman, R.W., The Surface Temperature Modification to the BBE Heat Transfer Program, APL/JHU EM-4272, 6/27/69.

8. Smith, G.D., Numerical Solution of Partial Differential Equations, Oxford University Press, London, 1965.

9. Allen, R.W., Surface Temperature Lumped Element Method Compared to Taylor's Series Method, APL/JHU EM-4169, Mar. 29, 1968.

10. Carslaw, H.S. and Jaeger, J.C., Conduction of Heat in Solids, Oxford University Press, London, 1959.

11. Elrod, H.G., New Finite Difference Technique for Solution of the Heat Conduction Equation, Especially Near Surfaces with Convective Heat Transfer, Trans. ASME, Vo1. 79, No. 7, pg. 1519, 1957.

12. Personal Communication with L. B. Weckesser of BBE/APL, December, 1973. 


\section{Appendix A}

\section{Consistency in One-Dimensional Variable Property Systems}

In this Appendix, the analysis leading to equation 25 for constant thermal property systems is extended to variable property systems. In a variable property system, one seeks an FDA to represent the equation:

$$
\rho c \frac{\partial T}{\partial t}=\frac{\partial k}{\partial x} \frac{\partial T}{\partial x}+k \frac{\partial^{2} T}{\partial x^{2}}
$$

Following the usual methods, for example around node 2 in Figure 4 , the energy balance equation would be:

$$
k_{1-2} \frac{\left(T_{1}-T_{2}\right)}{R \Delta x}=k_{2-3} \frac{\left(T_{2}-T_{3}\right)}{\Delta x}+(\rho c)_{2} V_{2} \frac{\left(T_{2}^{+}-T_{2}\right)}{\Delta t}
$$

Generally the conductivities are temperature dependent and are based on an average temperature when used in Equation A-2. $k_{1-2}$ and $k_{2-3}$ can be written as:

$$
\begin{aligned}
& \mathrm{k}_{1-2}=\mathrm{k}\left(\mathrm{aT}_{1}+\mathrm{bT}_{2}\right) \\
& \mathrm{k}_{2-3}=\mathrm{k}\left(\mathrm{aT}_{2}+\mathrm{bT}_{3}\right)
\end{aligned}
$$

where

$$
a+b=1
$$

Now the problem is to find out what $a, b$, and $v_{2}$ have to be so that equation A-2 is consistent with equation A-1. The method of analysis is very similar to the one leading to equation 25, i.e. $\mathrm{T}_{1}, \mathrm{~T}_{3}$ and $\mathrm{T}_{2}^{+}$have to be expanded about $\mathrm{T}_{2}$ (equations 22, 16, and 18) and substituted into equation $\mathrm{A}-2$. The difference is that $k_{1-2}$ and $k_{2-3}$ have to be expanded about $\left.\mathrm{k}_{2}=\mathrm{k}_{(\mathrm{T}}\right) \cdot \mathrm{T}_{1-2}$ is: 


$$
\begin{aligned}
k_{1-2}= & k\left(T_{2}-a \beta \Delta x\left(\frac{\partial T}{\partial x}\right)_{2}+o\left(\Delta x^{2}\right)\right)= \\
& k_{2}-a \beta \Delta x \frac{\partial k}{\partial T}\left(T_{2}\right)\left(\frac{\partial T}{\partial x}\right)_{2}+0\left(\Delta x^{2}\right)= \\
& k_{2}-a \beta \Delta x\left(\frac{\partial k}{\partial x}\right)_{2}+o\left(\Delta x^{2}\right)
\end{aligned}
$$

Similarly:

$$
\mathrm{k}_{2-3}=\mathrm{k}_{2}+\mathrm{b} \Delta \mathrm{x}\left(\frac{\partial \mathrm{k}}{\partial \mathrm{x}}\right)_{2}+0\left(\Delta \mathrm{x}^{2}\right)
$$

Putting the expanded expressions into equation $A-2$ and neglecting $0\left(\Delta x^{2}\right)$ terms leaves:

$$
\begin{gathered}
\Delta x\left(\frac{\beta+1}{2}\right) k_{2}\left(\frac{\partial^{2} T}{\partial x^{2}}\right)+(a \beta+b)\left(\frac{\partial k}{\partial x}\right)\left(\frac{\partial T}{\partial x}\right)_{2}= \\
(\rho c)_{2} v_{2}\left(\frac{\partial T}{\partial t}\right)_{2}
\end{gathered}
$$

Equation $A-7$ will reduce to equation $A-1$ if:

$$
v_{2}=\frac{\beta+1}{2} \Delta x
$$

and :

$$
a=b=\frac{1}{2}
$$

This shows that the volume allocation requirement is the same in variable property systems as in constant property systems. Furthermore equation A-9 shows that thermal conductivities used to determine control surface heat fluxes have to be based on the arithmetic ave rage of the temperatures of the two nodes surrounding the control surface for consistency. This practice has always been followed in the SHTP. 
Appendix B

Generalized IWC

Equation 31 was derived for a uniform grid system with the surface heat flux expressible as a constant surface conductance times an appropriate temperature difference. Often, the surface heat flux may not be so easily determined and there may be a need for a non-uniform grid system near the surface. is :

For a general surface heat flux $q_{S}^{\prime \prime}$, the surface boundary condition

$$
q_{S}^{\prime \prime}=-k\left(\frac{\partial T}{\partial x}\right)_{S}
$$

where $\mathrm{q}_{\mathrm{S}}^{\prime \prime}$ and $\mathrm{k}$ could be temperature dependent and $\mathrm{x}$ is measured in the direction of heat flow. If the grid system of Figure B-1 is used near the surface, with $\beta=1$ in general, $(\partial \mathrm{T} / \partial \mathrm{x})_{\mathrm{s}}=(\partial \mathrm{T} / \partial \mathrm{x})_{1}$ can be estimated to $O\left(\Delta x^{2}\right)$ from the following equations:

$$
\begin{gathered}
\mathrm{T}_{2}=\mathrm{T}_{1}+\beta \Delta x\left(\frac{\partial \mathrm{T}}{\partial \mathrm{x}}\right)_{1}+\beta^{2} \frac{\Delta \mathrm{x}^{2}}{2 !}\left(\frac{\partial^{2} \mathrm{~T}}{\partial \mathrm{x}^{2}}\right)_{1}+\beta^{3} \frac{\Delta \mathrm{x}^{3}}{3 !}\left(\frac{\partial^{3} \mathrm{~T}}{\partial \mathrm{x}^{3}}\right)_{1}+\cdot \cdot \\
\mathrm{T}_{3}=\mathrm{T}_{1}+(\beta+1) \Delta \mathrm{x}\left(\frac{\partial \mathrm{T}}{\partial \mathrm{x}}\right)_{1}+(\beta+1)^{2} \frac{\Delta \mathrm{x}^{2}}{2 !}\left(\frac{\partial^{2} \mathrm{~T}}{\partial \mathrm{x}^{2}}\right)_{1}+ \\
(\beta+1)^{3} \frac{\Delta \mathrm{x}^{3}}{3 !}\left(\frac{\partial^{3} \mathrm{~T}}{\partial \mathrm{x}^{3}}\right)_{1}+\cdots
\end{gathered}
$$

An $0\left(\Delta x^{2}\right)$ estimate of $(\partial \mathrm{T} / \partial \mathrm{x})_{1}$ can be found by eliminating $\left(\partial^{2} \mathrm{~T} / \partial \mathrm{x}^{2}\right)_{1}$ from these two equations, giving:

$$
\left(\frac{\partial T}{\partial x}\right)_{1}=\frac{1}{2 \beta^{2} \Delta x}\left((\beta+1)^{2} T_{2}-\beta^{2} T_{3}-(2 \beta+1) T_{1}\right)
$$

Combining this with equation $B-1$ results in the following possibly transcendental equation for $\mathrm{T}_{1}$ :

$$
q_{S}^{\prime \prime}\left(T_{1}\right)=\frac{k\left(T_{1}\right)}{2 \beta^{2} \Delta x}\left((2 \beta+1) T_{1}+\beta^{2} T_{3}-(\beta+1)^{2} T_{2}\right)
$$




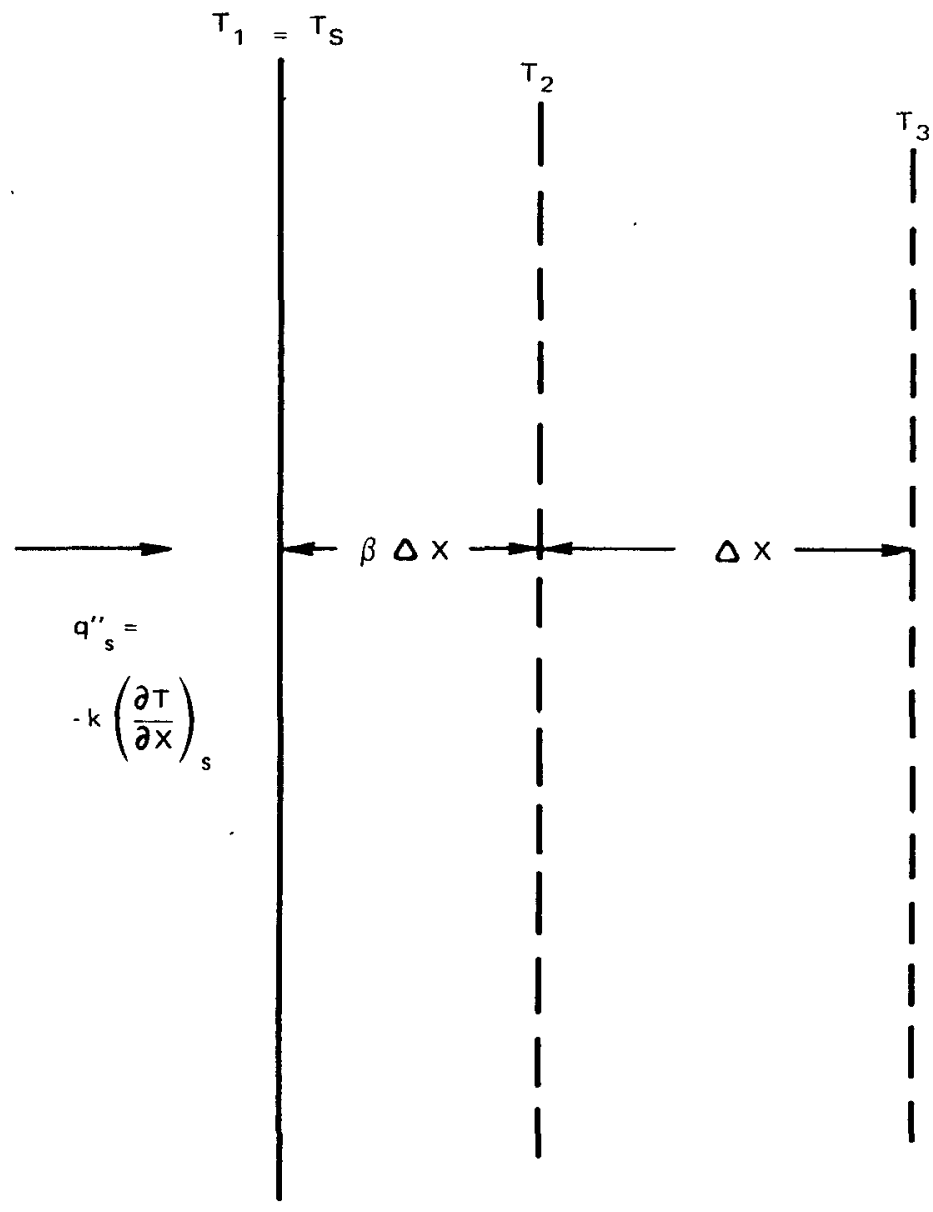

(U) Fig. B-1 NON-UNIFORM GRID FOR SURFACE HEAT FLUX ESTIMATION (U) 
THE JOHNS MOPKINS UNIVERSITY

APPLIED PHYSICS LABORATORY

Page 35.

If $\mathrm{T}_{1}$ cannot be found explicitly from this equation, it can be lound by the iterative methods currently used in the SHTP. 7 
Appendix C

Exact Solutions of the Slab Problem

Following are the analytical solutions for the two types of bath temperature variation considered in this memo.

For $F(t)=A t$, the temperature history is given by:

$$
\begin{gathered}
T(x, t)=T_{0}+\left(T^{*}-T_{0}\right)\left(1+\frac{A t}{T^{*}-T_{o}}\right. \\
+\frac{A}{T^{*}-T_{0}} \frac{L^{2}}{\alpha}\left(\frac{1}{2}\left(\frac{x}{L}\right)^{2}-\frac{x}{L}-\frac{k}{h L}\right) \\
\left.-2 \sum_{n=1}^{\infty} c_{n}(x, t)-2 \frac{A}{T^{*}-T_{0}} \frac{L^{2}}{\alpha} \sum_{n=1}^{\infty} \frac{C_{n}(x, t)}{\mu_{n}^{2}}\right)
\end{gathered}
$$

where $C_{n}(x, t)$ is given in equation 35 .

For $F(t)=A$ sin $w t$, the temperature history can be written down more easily if one adopts the following definitions.

$$
\begin{aligned}
& \lambda=\left(\frac{\omega}{2} \frac{\mathrm{L}^{2}}{\alpha}\right)^{1 / 2} \\
& B=\frac{h L}{k} \\
& \zeta=\lambda(1-x / L) \\
& \mathrm{H}_{1}=\lambda(\cosh \lambda \sin \lambda-\sinh \lambda \cos \lambda) \\
& \text { - } B \cosh \lambda \cos \lambda \\
& \mathrm{H}_{2}=\lambda(\cosh \lambda \sin \lambda+\sinh \lambda \cos \lambda) \\
& +B \sinh \lambda \sin \lambda \text { ) } \\
& z=-2 \lambda^{2} \sinh \lambda \cos \lambda(\sinh \lambda \cos \lambda+\cosh \lambda \sin \lambda) \\
& -2 B \lambda(\cosh \lambda \sinh \lambda-\cos \lambda \sin \lambda) \\
& -B^{2}\left(\sinh ^{2} \lambda-\sin ^{2} \lambda\right)
\end{aligned}
$$




$$
\begin{aligned}
& G_{1}(x)=B\left(H_{1} \cosh \zeta \cos \zeta-H_{2} \sinh \zeta \sin \zeta\right) / Z \\
& G_{2}(x)=B\left(H_{2} \cosh \zeta \cos \zeta+H_{1} \sinh \zeta \sin \zeta\right) / Z
\end{aligned}
$$

Now $T(x, t)$ can be written as:

$$
\begin{aligned}
& T(x, t)=T_{0}+\left(T^{*-T_{0}}\right)\left(1-2 \sum_{1}^{\infty} C_{n}(x, t)\right. \\
& +2 \frac{A}{T^{*}-T_{0}} \sum_{1}^{\infty} \frac{2 \lambda^{2} \mu_{n}^{2}}{\mu_{n}^{4}+4 \lambda^{4}} C_{n}(x, t) \\
& \left.+\frac{A}{T^{*}-T_{0}}\left(G_{1}(x) \sin \omega t+G_{2}(x) \cos \omega t\right)\right)
\end{aligned}
$$




\section{APPENDIX D}

Some Further Remarks Ahout IWC and SVE

This appendix was written in anticipation of questions which may arise over the fact that no surface volume term appears in the IWC surface heat flux equation (eq. 3I). As mentioned in the paragraph following equation 29, finding an $O\left(\Delta x^{2}\right)$ estimate of the wall temperature gradient eliminates the need for the volume term to appear explicitly in equation 31. The purpose of this appendix is to elahnrate further on this point.

The IWC method is an alternative to the SVE method. Both methods use the same grid point arrangement (Figure 2) and allocate the same volumes to each of the nodes in which the grid points are imbedded, $i . e$. node 1 has volume $\Delta x / 2$ while nodes 2,3 , etc. have the volume $\Delta x$. This choice of nodal volumes turns out to be a necessary requirement of consistency, as shown below.

Due to the choice of grid points in Figure 2, nodes 2, 3, etc. have to have the volume $\Delta x$ according to the consistency requirement in equation $A-8$ but this equation says nothing about the volume requirement of node 1 . The energy balance for node 1 is:

$$
-k_{1}\left(\frac{\partial T}{\partial x}\right)=k_{1-2} \frac{\left(T_{1}-T_{2}\right)}{\Delta x}+\left(\rho c_{1} \frac{v_{1}\left(T_{1}^{\dagger}-T_{1}\right)}{\Delta t}\right.
$$

The term $-k_{1}(\partial t / \partial x)_{1}$ is the wal1 heat $f$ lux $\left(h\left(T_{\infty}-T_{1}\right)\right.$ for the present $\quad 1$ problem). $V_{1}$ is the as ${ }_{1}$ yet unknown volume of node 1 , and $k_{1-2}$ is 1 evaluated at a temperature which is a weighted average of ${ }^{1-2} \mathrm{~T}_{1}$ and $\mathrm{T}_{2}$ expressible as (aT ${ }_{1}+$ $\mathrm{b} \mathrm{T}_{2}$ ) where $\mathrm{a}+\mathrm{b}=1$. As in Appendix $\mathrm{A}$, which considered interior nodes, the problem is to find values of $V_{1}$, a, and $b$ which will reduce equation $D-1$ to equation $A-1$ as $\Delta x$ and $\Delta t$ approach zero. Replacing $\mathrm{k}_{1-2}, \mathrm{~T}_{2}$, and $\mathrm{T}_{1}^{+}$with Taylor series expansions about $\mathrm{T}_{1}$ in equation $\bar{D}-1$ and neglecting $O\left(\Delta x^{2}\right)$ and $O(\Delta x \Delta t)$ terms gives:

$$
\begin{gathered}
0=\Delta x\left(-b\left(\frac{\partial k}{\partial x}\right)_{1}\left(\frac{\partial T}{\partial x}\right)_{1}-\frac{k}{2}\left(\frac{\partial^{2} T}{\partial x^{2}}\right)_{1}\right)+ \\
(\rho c)_{1} V_{1}\left(\frac{\partial T}{\partial t}\right)_{1}
\end{gathered}
$$

Consistency will be satisfied (i.e. equation D-2 will become equation $A-1)$ if:

$$
V_{1}=\frac{\Delta x}{2}
$$

and

$$
a=b=\frac{1}{2}
$$


Equation D-3 shows not only that there always has to be a surface volume element to satisfy consistency but, in view of equation A-8, that al1 nodal control surfaces in a grid system should be located halfway between adjacent grid points to guarantee consistency. This requirement also applies in two and three dimensional systems. Equation $D-4$ has the same significance as equation A-9.

With SVE, the wall heat $f$ lux term in equation $D-1$ is replaced by $h\left(T_{\infty}-T_{1}\right)$, which is the heat flux boundary condition. Thus in SVE one finds $\mathrm{T}_{1}^{+}$as a solution of the differential heat equation. IWC on the other hand replaces $-k_{1}(\partial \mathrm{T} / \partial \mathrm{x})$, with an $O\left(\Delta \mathrm{x}^{2}\right)$ finite difference estimate (eq. 30) and equates this to $h\left(T_{\infty}-T_{1}\right)$, as in equation 31. Now $T_{1}$ is found not from an FDA of the differential heat equation but from an FDA of the heat flux boundary condition. From the point of view of the interior nodes, $T_{1}$ is a temperature boundary condition in the IWC method.

The equivalence of IWC and SVE can be demonstrated by replacing $-k_{1}(\partial T / \partial x)$ in equation $D-1$ with its $O\left(\Delta x^{2}\right)$ FDA (eq. 30) and showing that the resultant equation is consistent with equation $A-1$. Putting equation 30 into equation $D-1$ gives:

$$
\begin{gathered}
-k_{1} \frac{4 \mathrm{~T}_{2}-3 \mathrm{~T}_{1}-\mathrm{T}_{3}}{2 \Delta \mathrm{x}}=\mathrm{k}_{1-2} \frac{\left(\mathrm{T}_{1}-\mathrm{T}_{2}\right)}{\Delta \mathrm{x}}+ \\
(\rho \mathrm{c})_{1} \frac{\Delta \mathrm{x}}{2} \frac{\left(\mathrm{T}_{1}^{+}-\mathrm{T}_{1}\right)}{\Delta \mathrm{t}}
\end{gathered}
$$

Making the appropriate Taylor series expansions about $T_{1}$ and $k_{1}$ shows that equation D-5 does indeed yield equation A-1 as $\Delta x$ and $\Delta t$ approach zero. This means that the right hand side of equation D-5 can be substituted into the right hand side of equation 31 , the IWC surface heat flux equation, and the end result is the SVE surface energy balance equation.

A further desirable property that SVE and hence IWC (since they are equivalent) have is that they properly account for all the energy put into the system being cousidered by convective heating. In terms of the slab problem being considered here, $\mathrm{E}_{\mathrm{I}}$, the convective energy input per unit area to the half slab is:

$$
E_{I}=\int_{0}^{t}\left(h\left(T_{\infty}(u)-T(0, u)\right) d u\right.
$$

This should balance the energy per unit area $E_{A}$, absorbed by half slab:

$$
E_{A}=\int_{0}^{L} \rho c\left(T(x, t)-T_{0}\right) d x
$$

so that: 


$$
\begin{gathered}
\int_{0}^{t} h\left(T_{\infty}(u)-T(0, u)\right) d u= \\
\int_{0}^{L} \rho c\left(T(x, t)-T_{0}\right) d x
\end{gathered}
$$

This equation is also a property of the differential heat equation, as shown below. Integrating both sides of equation A-1 with respect to $x$ from $x=0$ to $x=L$ gives:

$$
\int_{0}^{L} \rho c \frac{\partial T}{\partial t} d x=\int_{0}^{L} \frac{\partial}{\partial x} k \frac{\partial T}{\partial x} d x
$$

Since $\mathrm{x}=\mathrm{L}$ is an adiabatic $\mathrm{plane}$,

$$
\int_{0}^{L} \rho c \frac{\partial T}{\partial t} d x=-k\left(\frac{\partial T}{\partial x}\right)_{x=0}=h\left(T_{\infty}-T(0, T)\right)
$$

Integration of this equation with respect to time from $t=0$ to $t=t$ gives:

$$
\int_{0}^{t} h\left(T_{\infty}(u)-T(0, u)\right) d u=\int_{0}^{L} \rho c\left(T(x, t)-T_{0}\right) d x
$$

which is equation D-8. Since IWC and SVE both use consistent FDA's of the differential heat equation, they should give numerical quadrature equivalents of the integrals in equation D-8.

For node 1 (in Figure 2) the SVE heat balance gives:

$$
h\left(T_{\infty}-T_{1}\right)+\frac{k}{\Delta x}\left(T_{2}-T_{1}\right)=\rho c \frac{\Delta x}{2} \frac{\left(T_{1}^{+}-T_{1}\right)}{\Delta t}
$$

as does the combination of equations 31 and D-5 for IWC. For node 2 , one has:

$$
\frac{k}{\Delta x}\left(T_{1}-T_{2}\right)+\frac{k}{\Delta x}\left(T_{3}-T_{2}\right)=\rho c \Delta x \frac{\left(T_{2}^{+}-T_{2}\right)}{\Delta t}
$$

Similar equations apply all the way to node $N$, the slab's midplance node. Here, since nodes $N+1$ and $N-1$ have the same temperature, the heat balance equation is:

$$
\frac{k}{\Delta x}\left(T_{N-1}-T_{N}\right)=\rho c \frac{\Delta x}{2} \frac{\left(T_{N}^{+}-T_{N}\right)}{\Delta t}
$$

Adding equations D-11, D-12 etc., and D-13 gives:

$$
h\left(T_{\infty}-T_{1}\right)=\sum_{i=1}^{N} \gamma_{i} \rho c \frac{\left(T_{i}-T_{i}\right)}{\Delta t} \Delta x
$$


where $\gamma_{1}=\gamma_{N}=1 / 2$ and $\gamma_{i}=1$ for $1<i<N$. Equation D- 14 is the trapezolda 1 quadrature equivalent of equation $D-10$.

The total energy input per unit area by convection at a time $t=J \Delta t$ can be estimated by summing the contributions at each time level $j$ over the time periods $\Delta t$ from $j=0$ to $j=J$, i.e.:

$$
\sum_{j=1}^{J} h\left(T_{\infty}^{j}-T_{1}^{j}\right) \Delta t=\sum_{j=1}^{J} \sum_{i=1}^{N} \gamma_{i} \rho c \frac{\left(T_{i}^{j+1}-T_{i}^{j}\right)}{\Delta t} \Delta x \Delta t
$$

By performing the summations on $j$ on the right hand side of this equation, one can find that:

$$
\sum_{j=1}^{J} h\left(T_{\infty}^{j}-T_{1}^{j}\right) \Delta t=\sum_{i=1}^{N} \gamma_{i} \rho c\left(T_{i}^{J}-T_{o}\right) \Delta x
$$

which is the numerical quadrature equivalent of equation D-8.

The right hand side of equation D-15, which is trapezoidal, gives an $0\left(\Delta x^{2}\right)$ accurate estimation of the integral which it represents. This is also the order of accuracy of a 11 heat flux terms. The left hand side of equation $\mathrm{D}_{-}-15$ is rectangular and gives an $C(\Delta t)$ accurate estimation of $\int_{0}^{t} h\left(T_{\infty}(u)-T(0, u)\right) d u$.

This is consistent with the $0(\Delta t)$ accurate estimations of energy storage terms at individual nodes. 
THE JOHNS HOPKINS UNIVERSITY APPLIED PHYSICS LABORATORY SILVER SPRING MARYLAND

INITIAL DISTRIBUTION EXTERNAL TO THE APPLIED PHYSICS LABORATORY

ORGANIZATION

U. S. Atomic Energy Commission

Air Force Weapons Laboratory

NASA/AMES

NASA/ LANGLEY

Los Alamos Scientific Laboratory

Oak Ridge National Laboratory

Aerospace Corporation

Avco Systems

General Electric

Fairchild Industries

Teledyne Isotopes

TRW Systems

Westinghouse

Donald W. Douglas Laboratory

LOCATION

Germantown, Md.
ATTENT ION

G. L. Bennett

G. P. Dix

T. J. Dobry

N. Goldenberg

H. Jaffe

J. J. Lombardo

W. C. Remini

Albuquerque, N. M.

Moffett Field, Calif.

Hampton, Va .

Los Alamos, N. M.

Oak Ridge, Tenn.

Los Angles, Calif.

Wilmington, Mass.

King of Prussia, $\mathrm{Pa}$.

Germantown, Md.

Timonium, Md.

Redondo Beach, Calif.

Pittsburgh, $\mathrm{Pa}$.

Richland, Wash.
Capt. D. Egan

Lt. D. L. Tate

J. W. Vorreiter

G. D. Walberg

R. N. R. Mulford

J. Burns

R. G. Donne11y

J. C. Bailey

P. Levine

D. D. Knight

C. T. Bradshaw

H. P. Kling

D. C. Anderson

J. A. Segletes

J. M. Be 11

W. G. Parker

J. D. Watrous
COPIES

1

1

1

1

1

1

1

1

1

1

1

1

1

1

1

1

1

1

1

1

1

1

1 